\title{
Exogenous 2-(3,4-Dichlorophenoxy) triethylamine ameliorates the soil drought effect on nitrogen metabolism in maize during the pre-female inflorescence emergence stage
}

Tenglong Xie ${ }^{1}$, Wanrong Gu${ }^{1 *}\left(\mathbb{D}\right.$, Mingquan Wang ${ }^{2}$, Liguo Zhang ${ }^{2}$, Congfeng Li ${ }^{3}$, Caifeng $\mathrm{Li}^{1}$, Wenhua $\mathrm{Li}^{2}$, Lijie $\mathrm{Li}^{1}$ and Shi Wei ${ }^{1}$

\begin{abstract}
Background: Nitrogen ( $\mathrm{N}$ ) metabolism plays an important role in plant drought tolerance. 2-(3,4-Dichlorophenoxy) triethylamine (DCPTA) regulates many aspects of plant development; however, the effects of DCPTA on soil drought tolerance are poorly understood, and the possible role of DCPTA on nitrogen metabolism has not yet been explored.

Results: In the present study, the effects of DCPTA on N metabolism in maize (Zea mays L.) under soil drought and rewatering conditions during the pre-female inflorescence emergence stage were investigated in 2016 and 2017. The results demonstrated that the foliar application of DCPTA $(25 \mathrm{mg} / \mathrm{L})$ significantly alleviated drought-induced decreases in maize yield, shoot and root relative growth rate (RGR), leaf relative water content (RWC), net photosynthetic rate (Pn), stomatal conductance (Gs) and transpiration rate $(\mathrm{Tr})$, and nitrate $\left(\mathrm{NO}_{3}{ }^{-}\right)$, nitrite $\left(\mathrm{NO}_{2}{ }^{-}\right)$, soluble protein contents, and nitrate reductase (NR), nitrite reductase (NiR), isocitrate dehydrogenase (ICDH), alanine aminotransferase (AlaAT) and aspartate aminotransferase (AspAT) activities. In addition, the foliar application of DCPTA suppressed the increases of intercellular $\mathrm{CO}_{2}$ concentration $(\mathrm{Ci})$, ammonium $\left(\mathrm{NH}_{4}{ }^{+}\right)$and free amino acid contents, and the glutamate dehydrogenase $(\mathrm{GDH})$ and protease activities of the maize. Simultaneously, under drought conditions, the DCPTA application improved the spatial and temporal distribution of roots, increased the root hydraulic conductivity (Lp), flow rate of root-bleeding sap and $\mathrm{NO}_{3}{ }^{-}$delivery rates of the maize. Moreover, the DCPTA application protected the chloroplast structure from drought injury.

Conclusions: The data show, exogenous DCPTA mitigates the repressive effects of drought on $\mathrm{N}$ metabolism by maintained a stabilized supply of 2-oxoglutarate (2-OG) and reducing equivalents provided by photosynthesis via favorable leaf water status and chloroplast structure, and $\mathrm{NO}_{3}{ }^{-}$uptake and long-distance transportation from the roots to the leaves via the production of excess roots, as a result, DCPTA application enhances drought tolerance during the pre-female inflorescence emergence stage of maize.
\end{abstract}

Keywords: Maize, Soil drought, 2-(3,4-Dichlorophenoxy) triethylamine, Yield, Nitrogen metabolism

\footnotetext{
*Correspondence: wanronggu@163.com

${ }^{1}$ College of Agriculture, Northeast Agricultural University, No. 600, Changjiang

Street, Xiangfang District, Harbin, China

Full list of author information is available at the end of the article
}

(c) The Author(s). 2019 Open Access This article is distributed under the terms of the Creative Commons Attribution 4.0 International License (http://creativecommons.org/licenses/by/4.0/), which permits unrestricted use, distribution, and reproduction in any medium, provided you give appropriate credit to the original author(s) and the source, provide a link to the Creative Commons license, and indicate if changes were made. The Creative Commons Public Domain Dedication waiver (http://creativecommons.org/publicdomain/zero/1.0/) applies to the data made available in this article, unless otherwise stated. 


\section{Background}

Crops are frequently exposed to drought during the growth period because of limited and erratic rainfall patterns due to global climate change, which leads to restrictions on agricultural productivity worldwide [1]. Maize (Zea mays L.), an essential component of global food security, is widely cultivated around the word. The majority of the cultivated area of maize is almost wholly rain-fed and experiences sporadic drought and rewetting cycles [2]. However, maize is considered to be a drought-sensitive crop and loses approximately $1 / 4$ potential yield annually due to drought [3]. By 2050, the world population will reach 9 billion people, resulting in a high demand for maize (projected to double); furthermore, at that time, drought will severely restrict crop growth for more than $50 \%$ of the cultivated land [4].

To stabilize and increase global crop production to satisfy the demand of the globally burgeoning population, it is imperative to design agronomic research to improve maize performance under drought stress [5]. The application of plant growth regulators has been considered an effective way to enhance crop drought resistance [6]. Multiple investigations have indicated that a tertiary amine bioregulator known as 2-(3,4-dichlorophenoxy) triethylamine (DCPTA) regulates many aspects of plant development; for example, DCPTA promotes plant growth [7, 8], enlarges chloroplast volume [9], enhances photosynthetic enzyme activity [10], accelerates $\mathrm{CO}_{2}$ fixation [11], and stimulates carotenoid biosynthesis [12]. As far as we know, very few studies of DCPTA have focused on crops, and the effect of DCPTA on crops exposed to soil drought are still unclear.

Nitrogen $(\mathrm{N})$ metabolism is a fundamental process in determining the growth and productivity of plants [13]. After being taken up by root systems, nitrate $\left(\mathrm{NO}_{3}{ }^{-}\right)$is converted to nitrite $\left(\mathrm{NO}_{2}^{-}\right)$by nitrate reductase (NR), the first step of $\mathrm{N}$ uptake and utilization. Subsequently, nitrite $\left(\mathrm{NO}_{2}{ }^{-}\right)$is converted to $\mathrm{NH}_{4}{ }^{+}$by nitrite reductase $(\mathrm{NiR})$ with reduction-ferredoxin $\left(\mathrm{Fd}_{\text {red }}\right)$ as an electron donor [14]. Afterward, the ammonium $\left(\mathrm{NH}_{4}{ }^{+}\right)$, derived from $\mathrm{NO}_{3}{ }^{-}$reduction, photorespiration and/or other metabolic processes is assimilated into glutamine by the glutamine synthase/glutamine oxoglutarate aminotransferase (GS/GOGAT) cycle or the alternative glutamate dehydrogenase $(\mathrm{GDH})$ pathway with 2-oxoglutarate (2-OG) and reducing equivalents provided by photosynthesis [15]. Subsequently, glutamate serving as a donor of the amino group is used for the synthesis of other amino acids, which are used for the synthesis of various organic molecules such as chlorophyll, proteins and nucleic acids. The reactions are catalysed by aminotransferases such as alanine aminotransferase (AlaAT) and aspartate aminotransferase (AspAT) [16].
Drought disrupts $\mathrm{N}$ metabolism mainly via inhibiting the uptake and/or long-distance transportation of $\mathrm{NO}_{3}{ }^{-}$ [17], altering the activities of enzymes involved in $\mathrm{N}$ metabolism [18], inhibiting amino acid synthesis, and promoting protein hydrolysis [19]. At present, the study of plant growth regulators mainly concentrates on the improvement of photosynthesis and antioxidant systems, and there have been only a limited number of publications related to $\mathrm{N}$ metabolism.

Our previous hydroponic trial found that exogenous DCPTA drastically promoted growth under non-stress conditions and mitigated the PEG-simulated drought-induced growth inhibition of maize at the seedling stage by improving photosynthetic capacity [20] and modulating antioxidant system [21]. The present study was conducted to explore whether DCPTA can alleviate soil drought injuries to maize and whether the effects are associated with the modulation of $\mathrm{N}$ metabolism.

\section{Results \\ Effects of DCPTA on yield under soil drought and rewatering conditions}

From the time point of maize at the nine-leaf stage, irrigation was stopped for 20 days (during the pre-female inflorescence emergence stage) to form the drought conditions, and then rehydration. Drought stress significantly inhibited the maize yield (Fig. 1a and b). Compared with the well-watered treatment (plants were irrigated continuously), in the drought treatment, the grain number decreased by $29.23 \%$ in 2016 and $33.24 \%$ in 2017, and the grain yield decreased by $34.06 \%$ in 2016 and by $38.22 \%$ in 2017. However, the decrease in maize yield was partially recovered by DCPTA. Compared with the well-watered treatment, in the drought+DCPTA treatment, the grain number decreased by $14.01 \%$ in 2016 and by $16.55 \%$ in 2017 , and the grain yield decreased by $17.98 \%$ in 2016 and by $20.54 \%$ in 2017 . Moreover, the application of DCPTA improved maize yield under well-watered conditions. Compared with the well-watered treatment, in the DCPTA treatment, the grain number increased by $5.97 \%$ in 2016, and the grain yield increased by $7.31 \%$ in 2016 and by $8.02 \%$ in 2017 .

\section{Effects of DCPTA on relative growth rate (RGR) of shoot and root under soil drought and rewatering conditions} During the drought period, the shoot RGR decreased, the root RGR firstly increased and then decreased, and the RGR of shoot and root recovered during rehydration (Fig. 2a and b, Additional file 1). In the drought treatment compared with the control in 2016, the RGR of shoot and root decreased by $52.26 \%$ and by $48.59 \%$ at days 15-20, respectively; and by 39.76 and $37.70 \%$ at days 25-30, respectively. In the drought treatment compared with the control in 2017, the RGR of shoot and 


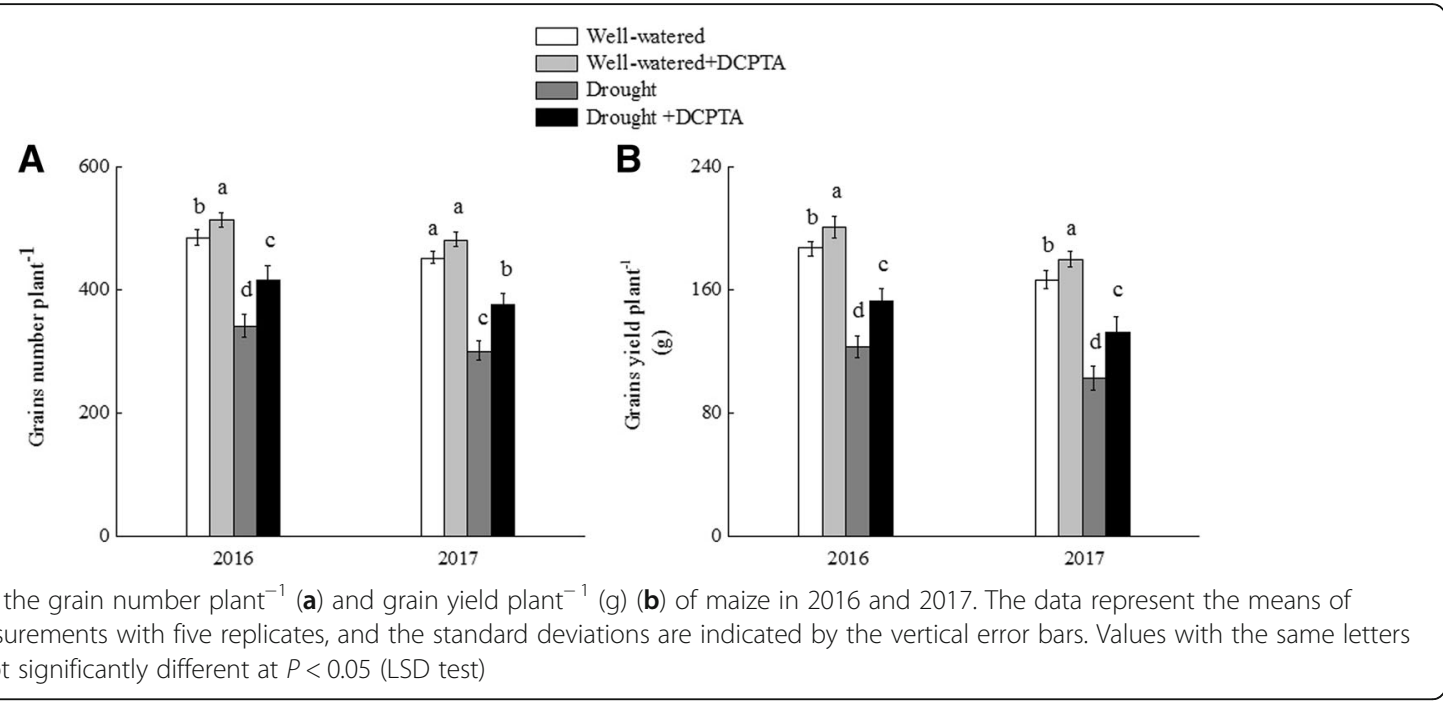

root decreased by 65.18 and $66.52 \%$ at days $15-20$, respectively; and by 51.97 and $43.74 \%$ at days $25-30$, respectively. However, the decrease in growth was partially recovered by DCPTA. In the drought+DCPTA treatment compared with the control in 2016, the RGR of shoot and root decreased by 29.96 and $26.31 \%$ at days $15-20$, respectively; and by 10.11 and $11.49 \%$ at days $25-30$, respectively. In the drought+DCPTA treatment compared with the control in 2017, the RGR of shoot and root decreased by 34.20 and $42.23 \%$ at days $15-20$, respectively; and by 12.41 and $14.75 \%$ at days $25-30$, respectively. Moreover, the application of DCPTA improved maize growth under well-watered conditions. The shoot RGR difference between the well-watered+DCPTA treatment and well-watered treatment was significant at days $15-20$ and days $25-30$ in 2016 , and days $10-15$, days $15-20$, days

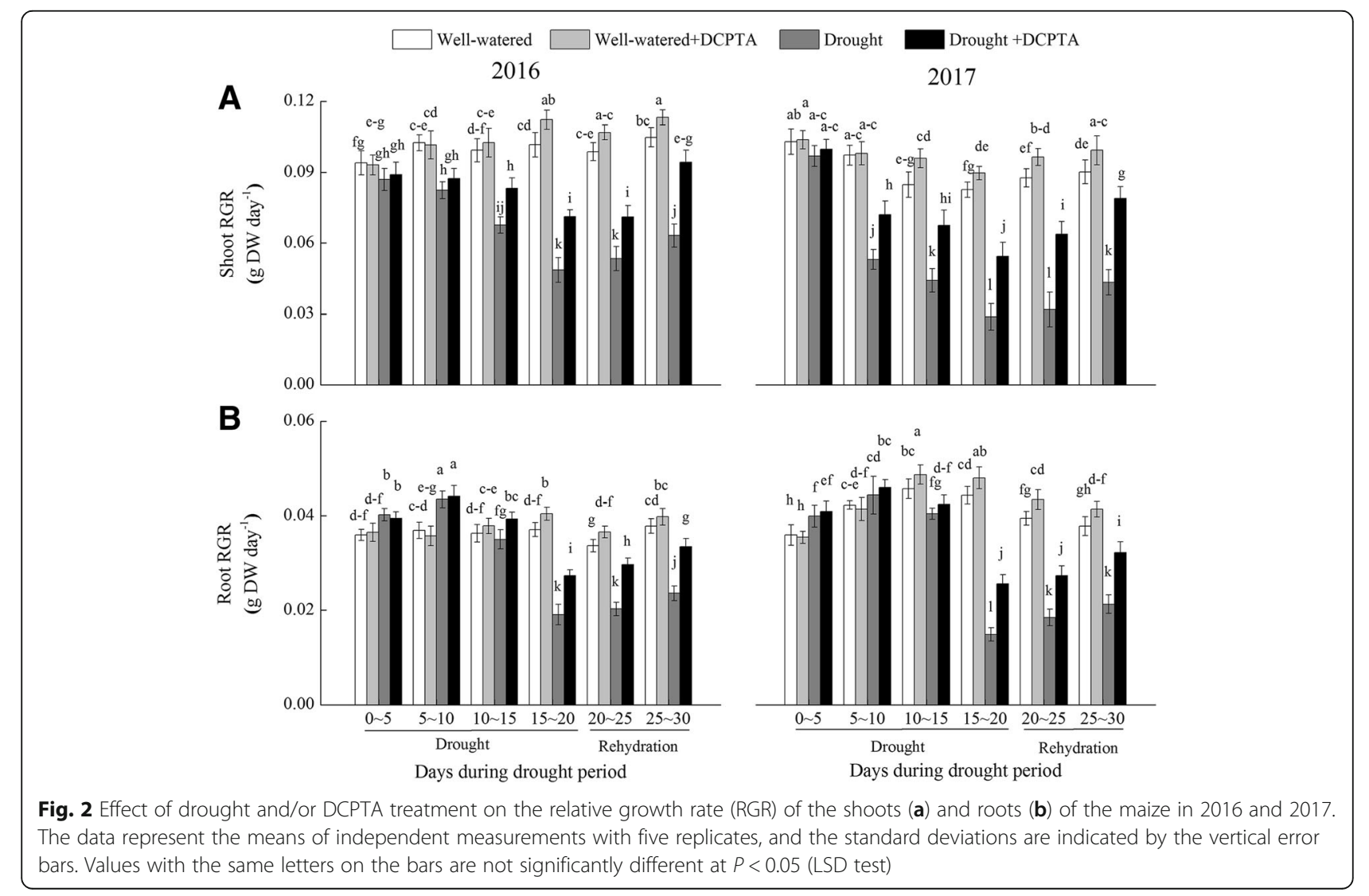


$20-25$ and days $25-30$ in 2017 , respectively. Similarly, the root RGR difference between the DCPTA treatment and well-watered treatment was significant at days 15-20 and days $20-25$ in 2016 , and days $10-15$, days $15-20$, days 20-25 and days 25-30 in 2017, respectively.

\section{Effects of DCPTA on root length density (RLD) and root surface area density (RSD) under soil drought and rewatering conditions}

Drought dramatically inhibited RLD and RSD in the 0-60 cm soil profile in 2016 and 2017 (Fig. 3a-d). On day 20, there was a significant difference in RLD for the drought treatment and drought+DCPTA treatment in $20-40 \mathrm{~cm}$ in 2016 and in $20-50 \mathrm{~cm}$ in 2017 , respectively. The RLD declines were partially reversed by rehydration. On day 30 , there were a significant difference in RLD for the drought treatment and drought+DCPTA treatment in $0-50 \mathrm{~cm}$ in both 2016 and 2017, and a significant difference in RLD for the well-watered treatment and well-watered+DCPTA treatment in $0-20 \mathrm{~cm}$ in both 2016 and 2017. On day 20 , there was a significant difference in RSD between the drought treatment and drought+DCPTA treatment in $10-40 \mathrm{~cm}$ in 2016 and $10-50 \mathrm{~cm}$ in 2017 . The declines in RSD were partially reversed by rehydration. On day 30, there were a significant difference in RSD between the drought treatment and drought +DCPTA treatment in $0-40 \mathrm{~cm}$ in 2016 and $0-50 \mathrm{~cm}$ in 2017, and a significant difference between RSD for the well-watered treatment and well-watered+DCPTA treatment in $0-20 \mathrm{~cm}$ in 2016 and in $0-30 \mathrm{~cm}$ in 2017.

Effects of DCPTA on root hydraulic conductivity, flow rate of root-bleeding sap and $\mathrm{NO}_{3}{ }^{-}$delivery rates under soil drought and rewatering conditions

The root hydraulic conductivity, flow rate of root-bleeding sap and $\mathrm{NO}_{3}{ }^{-}$concentrations in the root-bleeding sap declined continuously during the drought period and recovered during rehydration (Fig. 4a-c). In the drought treatment compared with the control, the root hydraulic conductivity, flow rate of root-bleeding sap and $\mathrm{NO}_{3}{ }^{-}$delivery rates decreased by $34.21,75.69$ and $76.58 \%$, respectively, on day 20 and by $19.34,35.96$ and $57.37 \%$, respectively, on day 30 in 2016; these values decreased by $47.01,78.80$ and $61.34 \%$, respectively, on day 20 and by $29.03,33.79$, and $50.47 \%$, respectively, on day 30 in 2017. However, the DCPTA application partially reversed the decline in root hydraulic conductivity, root-bleeding sap flow and $\mathrm{NO}_{3}{ }^{-}$ delivery rates caused by drought and resulted in a faster recovery after rehydration. In the drought+DCPTA treatment compared with the control, the root hydraulic conductivity, root-bleeding sap flow and $\mathrm{NO}_{3}{ }^{-}$delivery rates decreased by $17.91,46.73$ and $41.90 \%$, respectively, on day 20 and by $9.87,18.80$ and $23.51 \%$, respectively, on day 30 in 2016; these values decreased by 26.60 , 47.66 and $37.06 \%$, respectively, on day 20 and by 16.94 , 14.68 and $25.23 \%$, respectively, on day 30 in 2017 .

Under well-watered conditions, DCPTA significantly increased root hydraulic conductivity on the 15th, 20th, 25th and 30th days in 2016 and on the 20th and 25th days in 2017; DCPTA significantly increased the flow rate of root-bleeding sap on the 10th, 15th, 20th and 25th days in both 2016 and 2017; DCPTA significantly increased the $\mathrm{NO}_{3}{ }^{-}$concentration in root-bleeding sap on the 10th, 15th, 20th, 25th and 30th days in 2016 and on the 10th, 15th, 20th and 25th days in 2017.

\section{Effects of DCPTA on leaf relative water content (RWC) under soil drought and rewatering conditions}

The RWC declined continuously over the drought period and recovered during rehydration (Fig. 5). In the drought treatment compared with the control, RWC decreased by $30.88 \%$ on day 20 and by $13.08 \%$ on day 30 in 2016 and decreased by $37.48 \%$ on day 20 and by $21.89 \%$ on day 30 in 2017. However, the DCPTA application partially reversed the decline in RWC caused by drought and resulted in a faster recovery of the foliar RWC contents after rehydration. In the drought+DCPTA treatment compared with the control, the RWC decreased by $11.75 \%$ on day 20 and by $3.84 \%$ on day 30 in 2016 and decreased by $21.15 \%$ on day 20 and by $10.73 \%$ on day 30 in 2017. Under well-watered conditions, DCPTA application had no significant effect on the RWC.

\section{Effects of DCPTA on gas exchange parameters under soil} drought and rewatering conditions

$\mathrm{Pn}, \mathrm{Gs}$ and $\mathrm{Tr}$ declined continuously over the drought period and recovered during rehydration (Fig. 6a-c). In the drought treatment compared with the control, Pn, Gs and $\operatorname{Tr}$ decreased by $46.20,68.97$ and $51.35 \%$, respectively, on day 20 and by $35.06,46.30$ and $38.17 \%$, respectively, on day 30 in 2016 and decreased by 56.00 , 71.10 and $62.10 \%$, respectively, on day 20 and by 45.89 , 44.02 and $43.79 \%$, respectively, on day 30 in 2017 . However, the DCPTA application partially reversed the decline in Pn, Gs and Tr caused by drought and resulted in a faster recovery of $\mathrm{Pn}, \mathrm{Gs}$ and $\mathrm{Tr}$ after rehydration. In the drought+DCPTA treatment compared with the control, Pn, Gs and Tr decreased by 23.41, 37.39 and $20.95 \%$, respectively, on day 20 and by $8.77,20.89$ and $10.61 \%$, respectively, on day 30 in 2016 and decreased by $35.31,32.03$ and $34.11 \%$, respectively, on day 20 and by $14.16,15.33$ and $8.62 \%$, respectively, on day 30 in 2017 . Under well-watered conditions, DCPTA significantly increased Pn on the 10th, 15th, 25th and 30th days in 2016 and on the 15th, 20th and 25th days in 2017. In addition, under well-watered conditions, DCPTA 

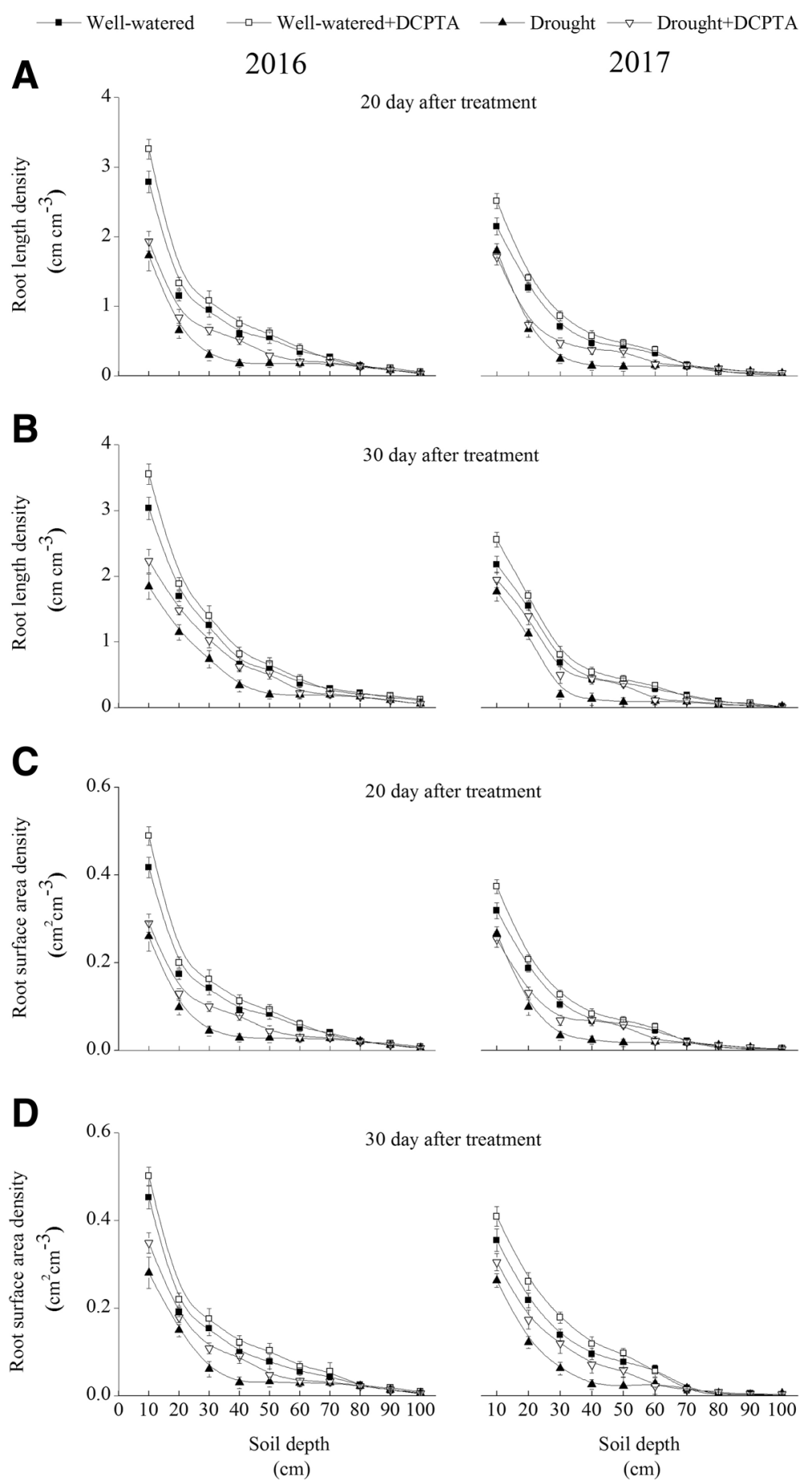

Fig. 3 Effect of drought and/or DCPTA treatment on root length density (RLD) (a, b) and root surface area density (RSD) (c, d) for different soil depths on the 20th day and 30th day after treatment in 2016 and 2017

significantly increased Gs on the 15th, 20th, 25th and 30th days in 2016 and on the 10th, 15th, 20th, 25th and 30th days in 2017 and significantly increased $\operatorname{Tr}$ on the 10th, 15th, 20th, 25th and 30th days in both 2016 and 2017.
In 2016 and 2017, Ci showed the same variation tendency during the drought period (Fig. 6d). In the drought treatment, $\mathrm{Ci}$ declined over days $0-10$, subsequently increased over days $10-20$, and then decreased after rehydration. In the drought+DCPTA treatment, Ci 


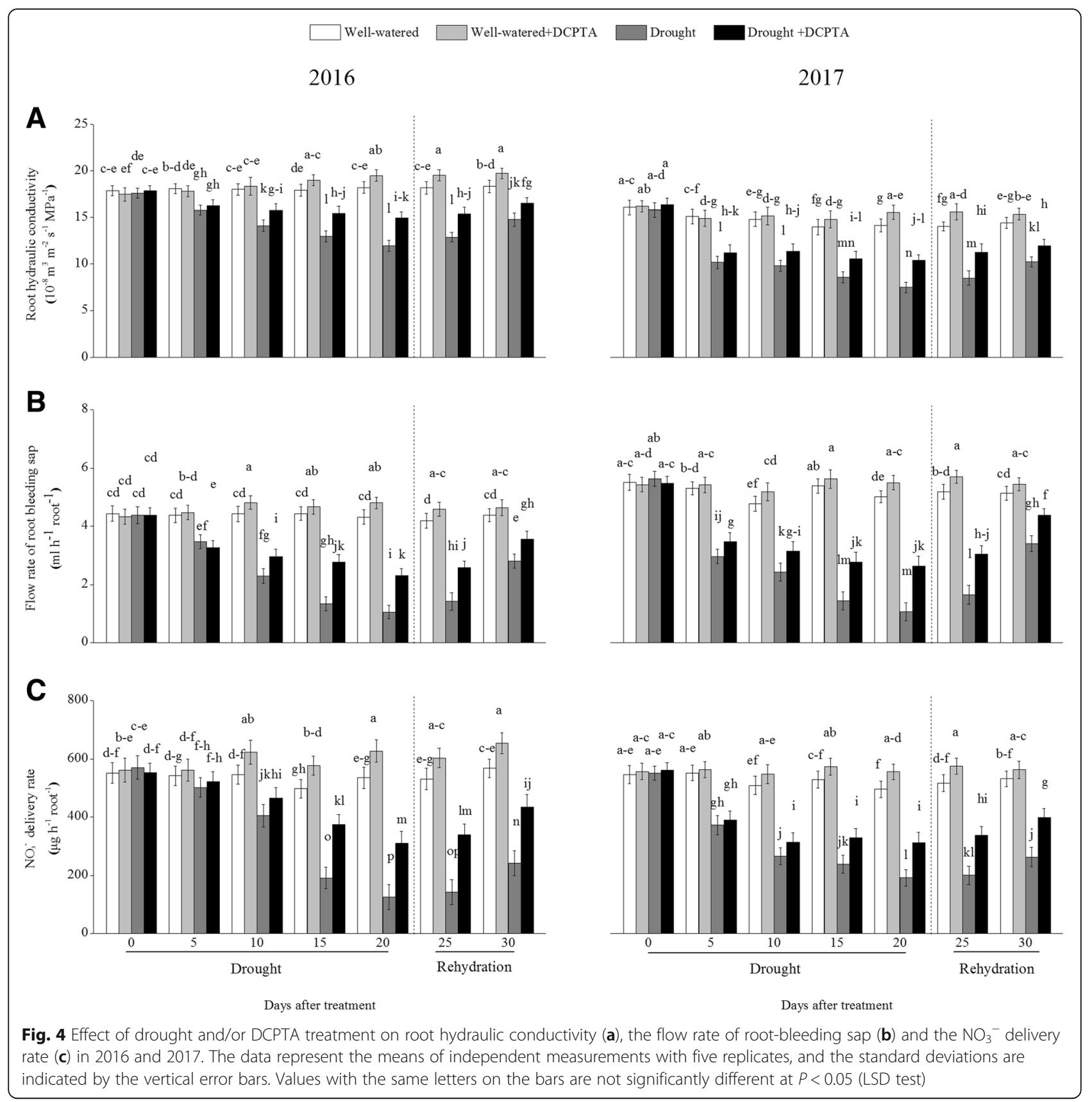

declined over days $0-15$ day and subsequently increased over days 15-30. Under well-watered conditions, DCPTA application had no significant effect on Ci.

\section{Effects of DCPTA on chloroplast ultrastructure under soil drought and rewatering conditions}

Regardless of whether DCPTA was applied, the photosynthetic mesophyll cells of the non-stressed seedlings included a delimited cell wall containing chloroplasts (Fig. 7a, b, e and f). These chloroplasts had intact membranes and a regular arrangement of granal and stromal thylakoids, which were attached to the cell wall and exhibited typical ellipsoidal shapes. However, in the stressed seedlings, the cell wall structure was incomplete and exhibited indistinct gradation, a lower density, and loose edges (Fig. 7c and h). Plasmolysis and degradation were also evident in part of the cell membrane. Moreover, the chloroplasts, which separated from the plasma membrane, were nearly round and swelled asymmetrically, the thylakoids were overly disorganized, and the thylakoid membranes were loose and showed an increased number of plastoglobules. In the PEG-6000 + DCPTA treatment, the complete membrane structures of the chloroplasts were present, and the shapes of the 


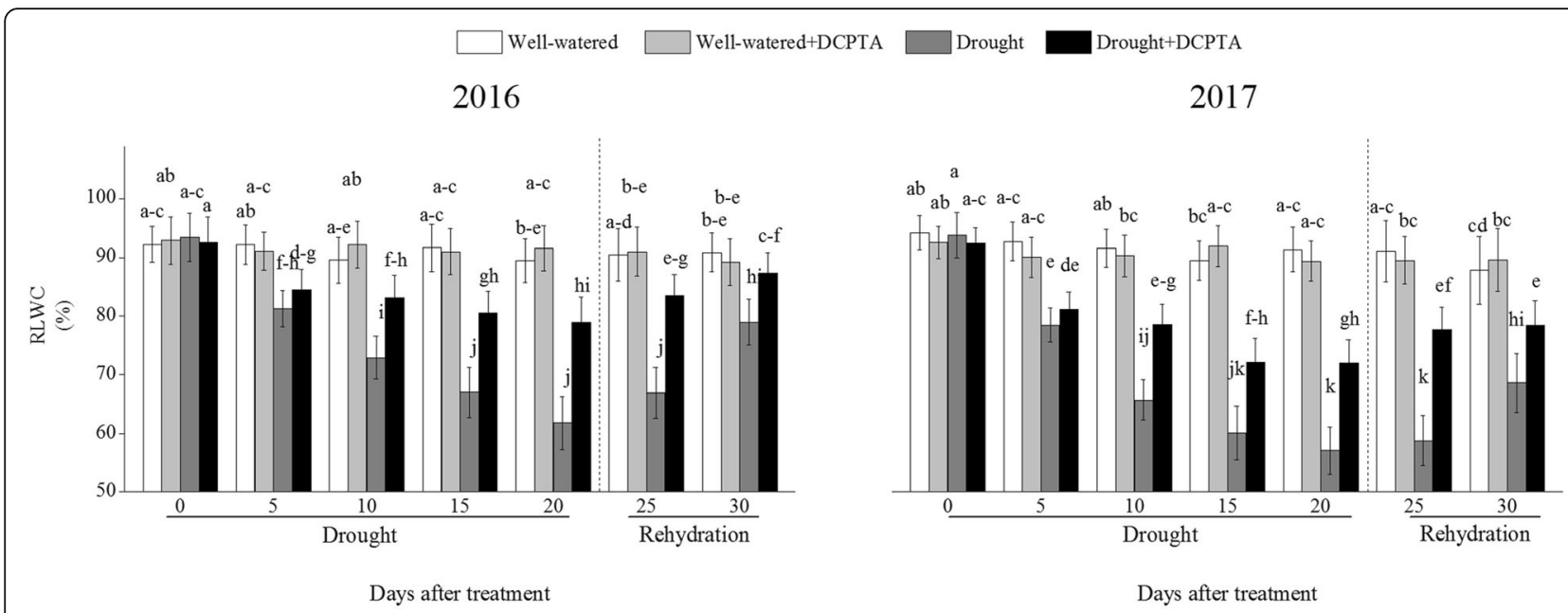

Fig. 5 Effect of drought and/or DCPTA treatment on relative water content of the leaves (RWC) in 2016 and 2017. The data represent the means of independent measurements with five replicates, and the standard deviations are indicated by the vertical error bars. Values with the same letters on the bars are not significantly different at $P<0.05$ (LSD test)

chloroplasts changed slightly from elongated ellipses to ellipses close to the cell walls (Fig. 7d and i). A well-aligned internal lamellar system and fewer plastoglobules were observed in the leaves of the PEG-6000 + DCPTA treatment compared with the leaves of the PEG-6000 treatment.

\section{Effects of DCPTA on ICDH activity under soil drought and rewatering conditions}

ICDH activity declined continuously over the drought period and recovered during rehydration (Fig. 8). In the drought treatment compared with the control, ICDH activity decreased by $40.75 \%$ on day 20 and by $36.33 \%$ on day 30 in 2016 and decreased by $37.77 \%$ on day 20 and by $33.07 \%$ on day 30 in 2017. However, the DCPTA application partially reversed the decline in ICDH activity caused by drought and resulted in a faster recovery of ICDH activity after rehydration. In the drought+DCPTA treatment compared with the control, ICDH decreased by $24.92 \%$ on day 20 and by $19.94 \%$ on day 30 in 2016 and decreased by $19.88 \%$ on day 20 and by $13.63 \%$ on day 30 in 2017. Under well-watered conditions, the application of DCPTA significantly increased the foliar ICDH activity on the 10th, 15th, 20th and 25th days in 2016 and on the 15th, 20th, and 25th days in 2017.

\section{Effects of DCPTA on contents of $\mathrm{NO}_{3}{ }^{-}, \mathrm{NO}_{2}{ }^{-}$and $\mathrm{NH}_{4}{ }^{+}$ under soil drought and rewatering conditions}

The foliar $\mathrm{NO}_{3}{ }^{-}$and $\mathrm{NO}_{2}{ }^{-}$contents declined continuously during the drought period and recovered during rehydration (Fig. 9a and b). In the drought treatment compared with the control, the foliar $\mathrm{NO}_{3}{ }^{-}$and $\mathrm{NO}_{2}{ }^{-}$ contents decreased by 39.82 and $38.27 \%$, respectively, on day 20 and by 33.62 and $35.11 \%$, respectively, on day 30 in 2016 and decreased by 57.97 and $32.27 \%$, respectively, on day 20 and by 42.38 and $25.21 \%$, respectively, on day 30 in 2017. However, the DCPTA application partially reversed the decline in the foliar $\mathrm{NO}_{3}{ }^{-}$and $\mathrm{NO}_{2}{ }^{-}$contents caused by drought and resulted in a faster recovery of the foliar $\mathrm{NO}_{3}{ }^{-}$and $\mathrm{NO}_{2}{ }^{-}$contents after rehydration. In the drought+DCPTA treatment compared with the control, the foliar $\mathrm{NO}_{3}{ }^{-}$and $\mathrm{NO}_{2}{ }^{-}$contents decreased by 25.94 and $23.31 \%$, respectively, on day 20 and by 14.25 and $18.55 \%$, respectively, on day 30 in 2016 and decreased by 33.86 and $18.26 \%$, respectively, on day 20 and by 17.26 and $8.60 \%$, respectively, on day 30 in 2017 . In contrast, drought led to a marked elevation in the foliar $\mathrm{NH}_{4}{ }^{+}$content (Fig. 9c). In the drought treatment compared with the control, the foliar $\mathrm{NH}_{4}{ }^{+}$increased by $52.48 \%$ on day 20 and by $29.18 \%$ on day 30 in 2016 and increased by $98.68 \%$ on day 20 and by $72.21 \%$ on day 30 in 2017. In contrast, the DCPTA application suppressed the increase in the foliar $\mathrm{NH}_{4}{ }^{+}$content induced by drought. In the drought+DCPTA treatment compared with the control, the foliar $\mathrm{NH}_{4}{ }^{+}$increased by $20.83 \%$ on day 20 and by $13.33 \%$ on day 30 in 2016 and increased by $45.37 \%$ on day 20 and by $33.29 \%$ on day 30 in 2017 .

Under well-watered conditions, DCPTA significantly increased the foliar $\mathrm{NO}_{3}{ }^{-}$content on the 20th and 25th days in 2016 and on the 15th, 20th, 25th and 30th days in 2017. However, the DCPTA application had no significant effect on the foliar contents of $\mathrm{NO}_{2}{ }^{-}$and $\mathrm{NH}_{4}{ }^{+}$.

\section{Effects of DCPTA on activities of NR and NiR under soil drought and rewatering conditions}

The activities of foliar NR and NiR declined continuously during the drought period and recovered during rehydration (Fig. 10a and b). In the drought treatment 
- Well-watered 2016

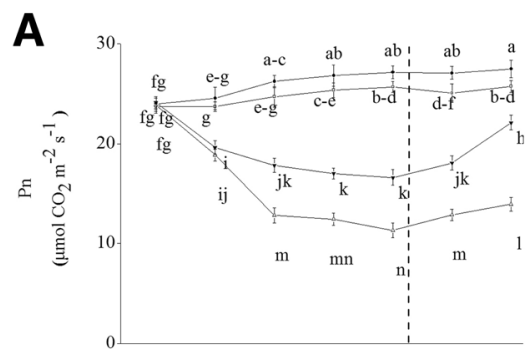

B 0.3
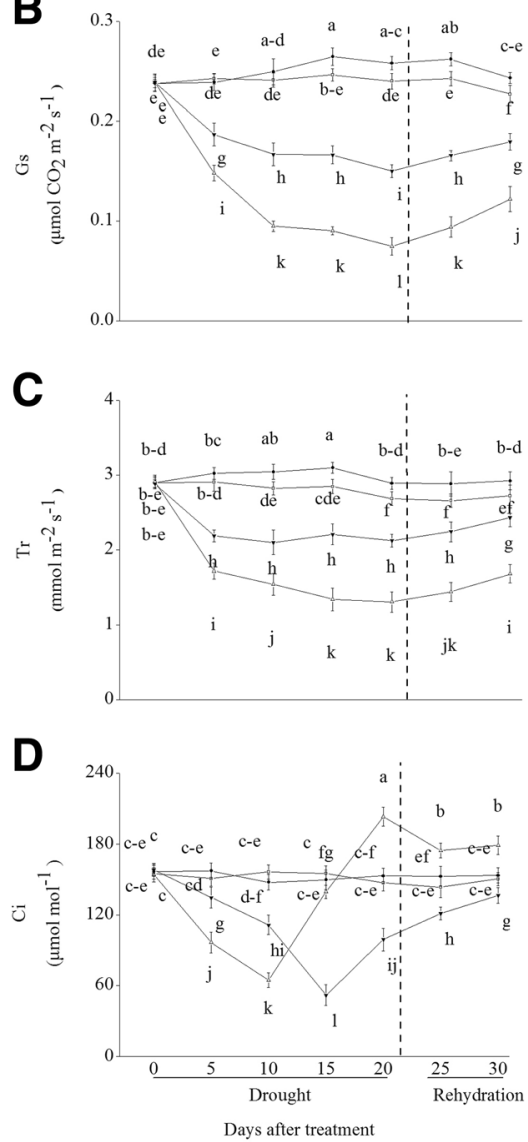

-Drought+DCPTA 2017
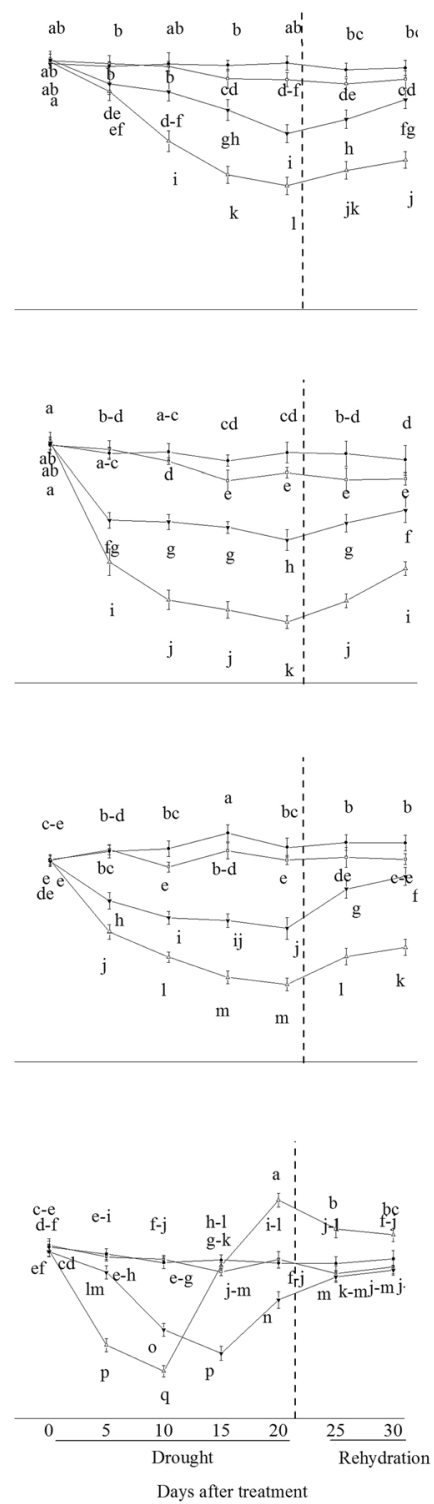

Fig. 6 Effect of drought and/or DCPTA treatment on the gas exchange parameters in the maize leaves in 2016 and 2017 . Pn, net photosynthetic rate (a); Gs, stomatal conductance $(\mathbf{b})$; $T r$, transpiration rate $(\mathbf{c})$; $\mathrm{Ci}$, intercellular $\mathrm{CO}_{2}$ concentration (d). The data represent the means of independent measurements with five replicates, and the standard deviations are indicated by the vertical error bars. Values with the same letters on the bars are not significantly different at $P<0.05$ (LSD test)

compared with the control treatment, the activities of foliar NR and NiR decreased by 40.37 and $36.91 \%$, respectively, on day 20 and by 34.42 and $29.82 \%$, respectively, on day 30 in 2016 and decreased by 52.80 and $32.46 \%$, respectively, on day 20 and by 37.36 and $21.28 \%$, respectively, on day 30 in 2017. However, the DCPTA application partially reversed the declines in the activities of foliar NR and NiR caused by drought and resulted in a faster recovery of the foliar NR and NiR activities after rehydration. In the drought+DCPTA treatment compared with the control, the activities of foliar NR and NiR decreased by 15.54 and $14.21 \%$, respectively, on day 20 and by 10.79 and $7.79 \%$, respectively, on day 30 in 2016 and decreased by 25.10 and $12.39 \%$, respectively, on day 20 and by 13.55 and $4.96 \%$, respectively, on day 30 in 2017. Under well-watered conditions, DCPTA significantly increased the foliar NR activity on the 10th, 15 th and 25th days in 2016 and on the 10th, 15th, 20th 

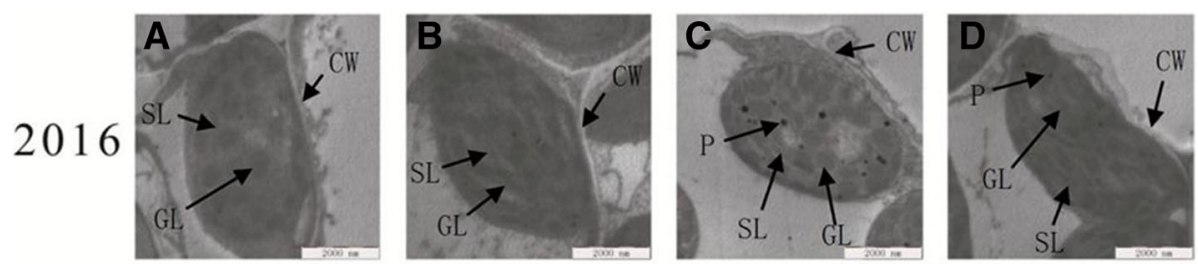

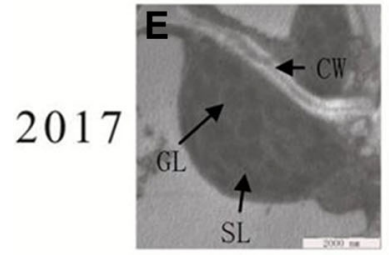

Well-watered

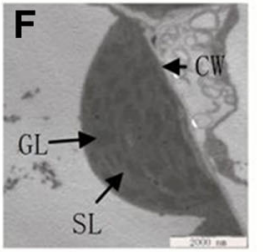

Well-watered

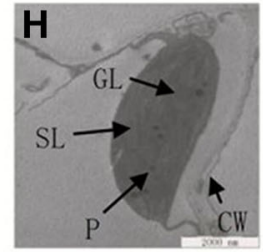

Drought

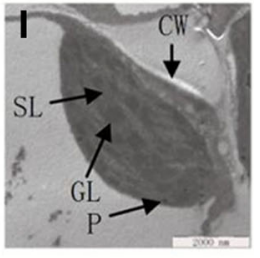

Drought

Fig. 7 Ultrastructure of the photosynthetic apparatus in the maize leaves after 20 days of well-watered treatment (a, e), well-watered+DCPTA treatment (b, f), drought treatment $(\mathbf{c}, \mathbf{h})$, and drought+DCPTA treatment (d, i) in 2016 and 2017. SL, stroma lamella; GL, grana lamellae; CW, cell wall; and P, plastoglobule. The scale bars for the photosynthetic apparatus represent $2000 \mathrm{~nm}$

and 25th days in 2017. Similarly, under well-watered conditions, DCPTA significantly increased the foliar NiR activity on the 10th and 25th days in 2016 and on the 15th and 20th days in 2017.

\section{Effects of DCPTA on activities of GS, GOGAT and GDH under soil drought and rewatering conditions}

The foliar GS activity first increased and then decreased, and the foliar GOGAT activity decreased continuely during the drought period and recovered during rehydration (Fig. 11a and b). In the drought treatment compared with the control, the activities of foliar GS and GOGAT decreased by 40.69 and $60.62 \%$, respectively, on day 20 and by 33.65 and $51.39 \%$, respectively, on day 30 in 2016 and decreased by 47.57 and $66.84 \%$, respectively, on day 20 and by 37.96 and 56.77\%, respectively, on day 30 in 2017 . However, the DCPTA application partially reversed the decline in the foliar GS and GOGAT activities caused by drought and resulted in a faster recovery of the foliar GS and GOGAT activities after rehydration. In the drought +DCPTA treatment compared with the control, the foliar GS and GOGAT activities decreased by 19.87 and 33.37\%, respectively, on day 20 and by 10.99 and $15.17 \%$, respectively, on day 30 in 2016 and decreased by 23.56 and $33.02 \%$, respectively, on day 20 and by 14.93 and $18.20 \%$, respectively, on day 30 in 2017. Likewise, the DCPTA application alone caused an increase in the foliar GS and GOGAT activities. Under well-watered conditions,

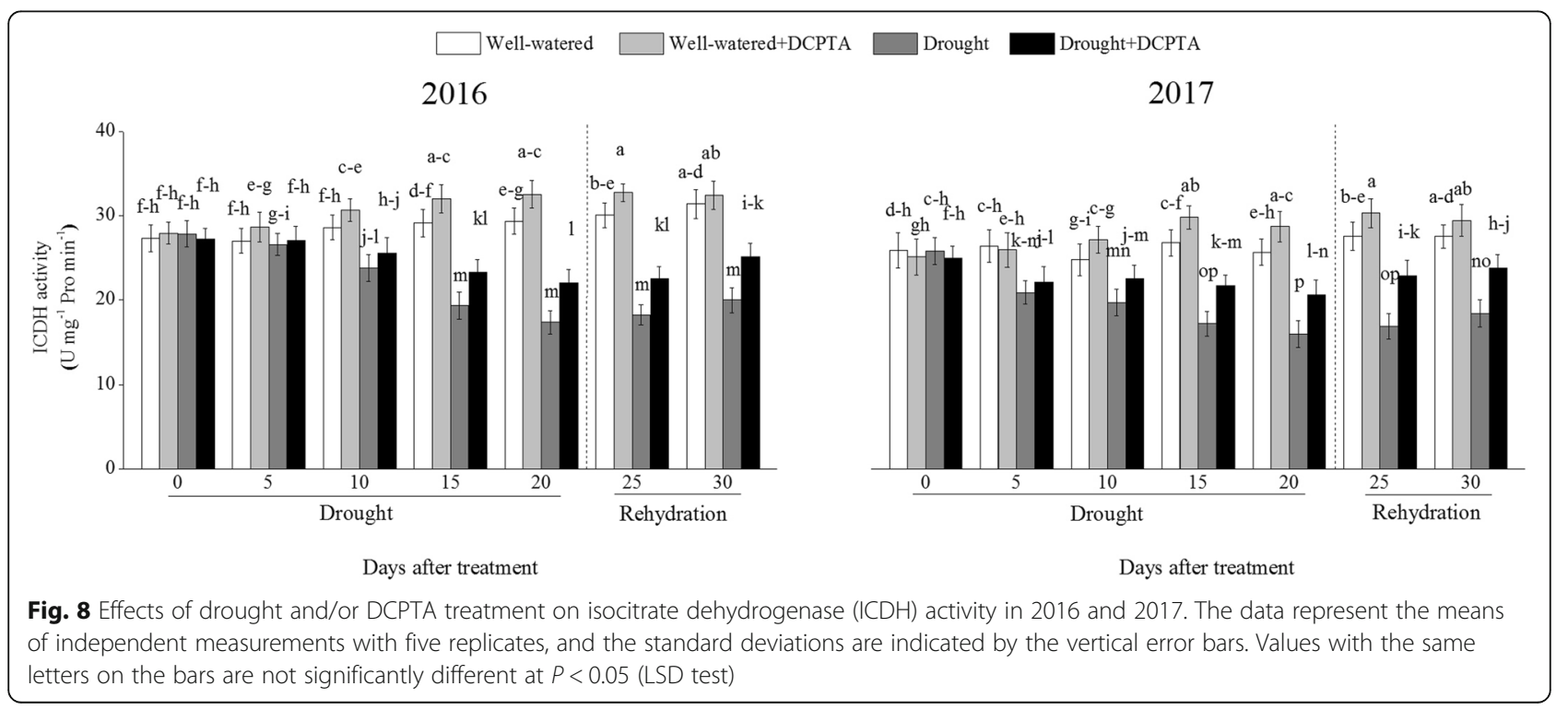




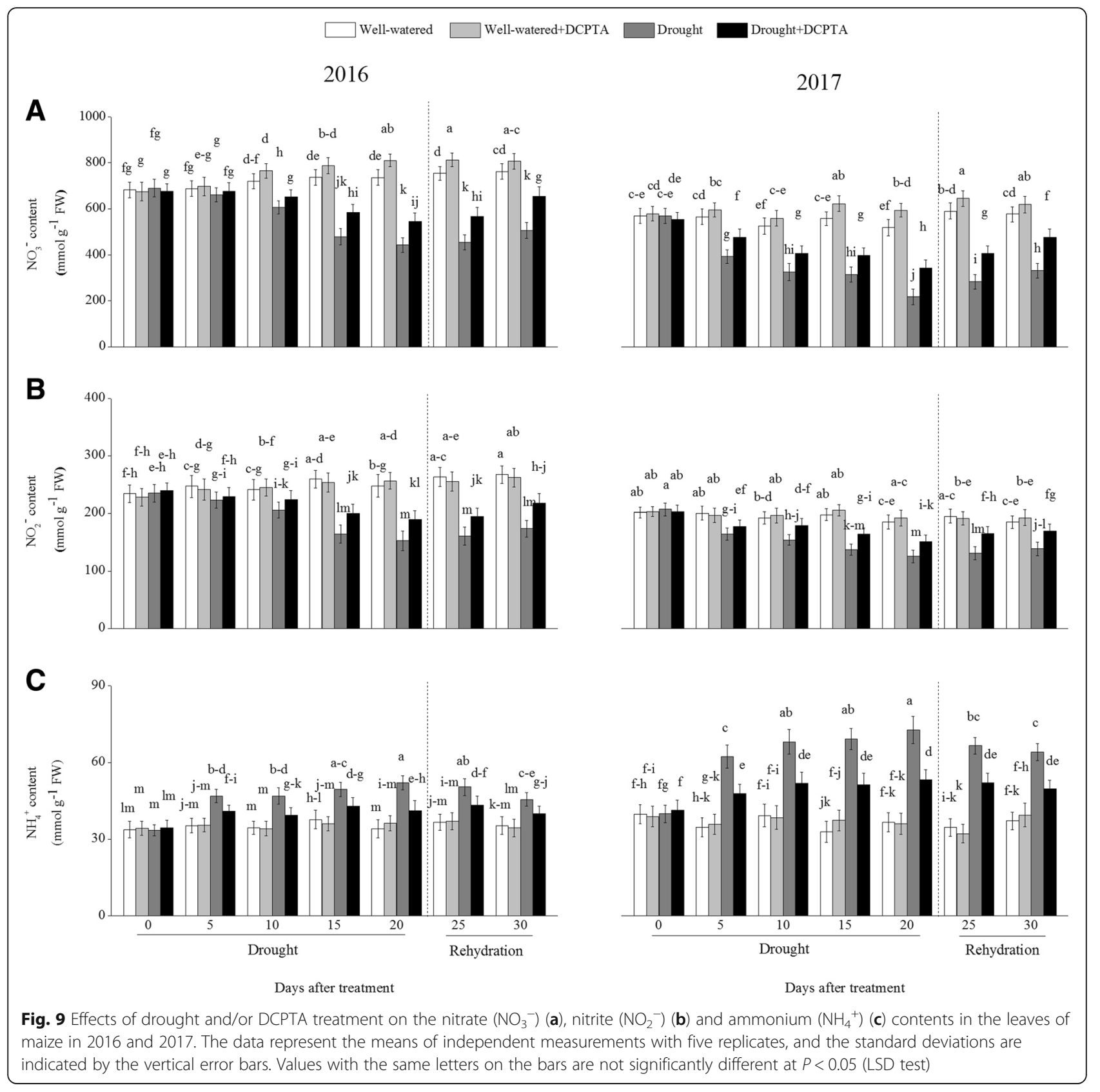

DCPTA significantly increased the foliar GS activity on day 20 and day 25 in 2016 and on day 10, day 20 and day 25 in 2017, increased the foliar GOGAT activity on day 15 in 2017. In contrast, drought led to marked increases in the activities of foliar NAD-GDH and NADH-GDH (Fig. 11c and d). In the drought treatment compared with the control, the activities of foliar NAD-GDH and NADH-GDH increased by 87.16 and $150.92 \%$, respectively, on day 20 and by 84.01 and $134.71 \%$, respectively, on day 30 in 2016 and increased by 103.99 and 137.36\%, respectively, on day 20 and by 96.13 and $111.20 \%$, respectively, on day 30 in 2017. However, the DCPTA application partially reversed the increases in the activities of foliar NAD-GDH and NADH-GDH caused by drought and resulted in a faster recovery of the foliar NAD-GDH and NADH-GDH activities after rehydration. In the drought +DCPTA treatment compared with the control, the activities of foliar NAD-GDH and NADH-GDH increased by 49.55 and $92.59 \%$, respectively, on day 20 and by 36.52 and $49.51 \%$, respectively, on day 30 in 2016 and increased by 46.90 and $80.94 \%$, respectively, on day 20 and by 35.43 and $45.60 \%$, respectively, on day 30 in 2017. Under well-watered conditions, DCPTA significantly increased the foliar NAD-GDH activity on day 15 in 2016. 


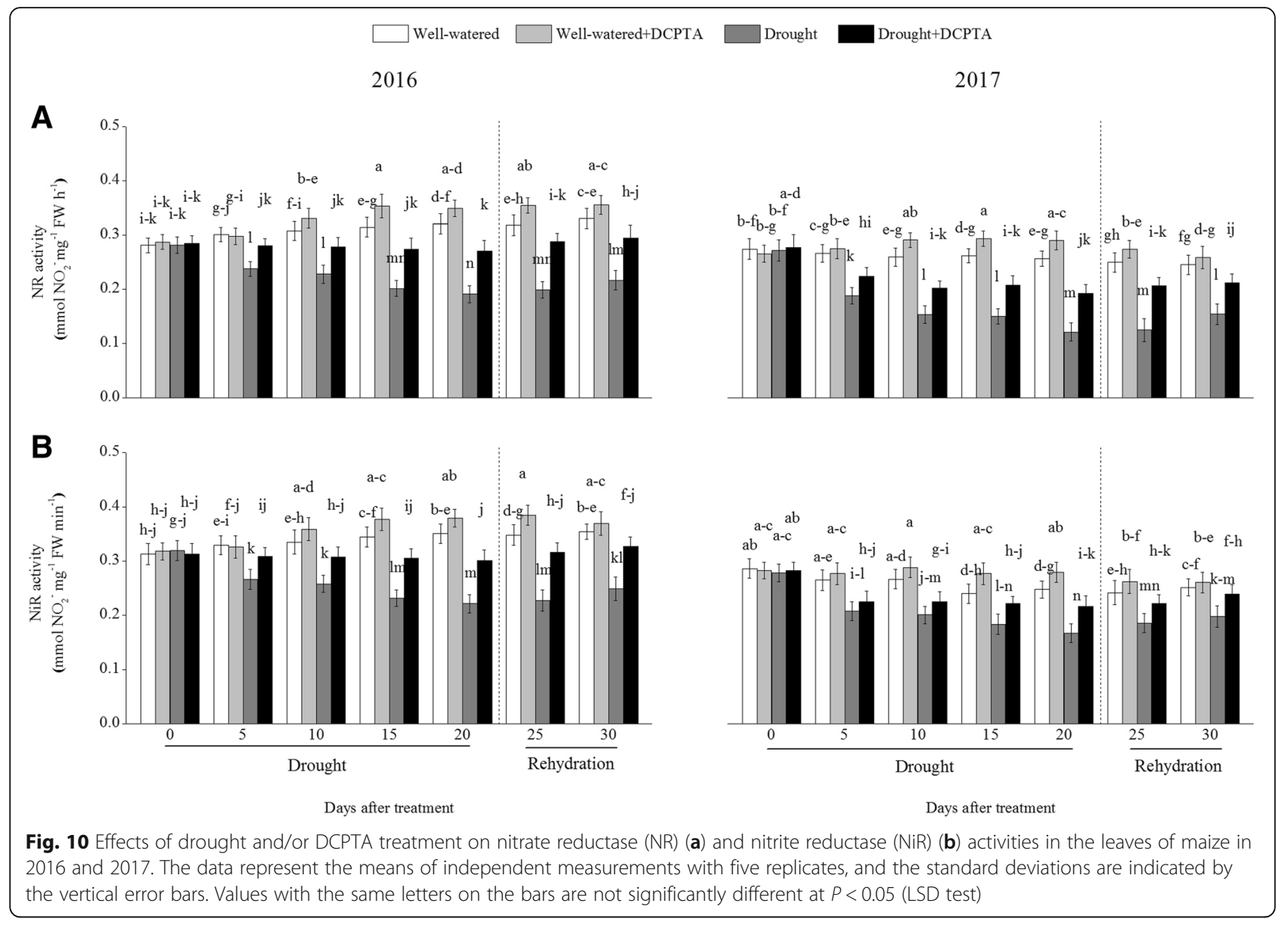

Effects of DCPTA on activities of AlaAT and AspAT under soil drought and rewatering conditions

The activities of foliar AlaAT and AspAT first increased and then continuously decreased during the drought period and recovered during rehydration (Fig. 12a and b). In the drought treatment compared with the control, the activities of foliar AlaAT and AspAT decreased by 44.18 and $65.51 \%$, respectively, on day 20 and by 36.43 and $38.52 \%$, respectively, on day 30 in 2016 and decreased by 56.80 and $54.92 \%$, respectively, on day 20 and by 41.43 and 41.29\%, respectively, on day 30 in 2017 . However, the DCPTA application partially reversed the decline in the activities of foliar AlaAT and AspAT caused by drought and resulted in a faster recovery of the foliar AlaAT and AspAT activities after rehydration. In the drought+DCPTA treatment compared with the control, the activities of foliar AlaAT and AspAT decreased by 17.45 and $35.39 \%$, respectively, on day 20 and by 15.84 and $17.17 \%$, respectively, on day 30 in 2016 and decreased by 32.49 and $37.82 \%$, respectively, on day 20 and by 17.46 and 18.21\%, respectively, on day 30 in 2017.

Under well-watered conditions, DCPTA significantly increased the foliar AlaAT activity on day 10, day 15, and day 20 in 2016 and on day 10, day 15, day 20 and day 25 in 2017. Similarly, under well-watered conditions, DCPTA significantly increased the foliar AspAT activity on day 15 in 2016 and on day 5, day 10, day 15 and day 25 in 2017.

\section{Effects of DCPTA on protease activity, and contents of proteins and free amino acids under soil drought and rewatering conditions}

The protease activity and free amino acid contents increased continuously during the drought period and decreased during rehydration (Fig. 13a and c). In the drought treatment compared with the control, the protease activity and free amino acid contents increased by 122.48 and $88.92 \%$, respectively, on day 20 and by 55.03 and $34.51 \%$, respectively, on day 30 in 2016 and increased by 145.15 and $78.58 \%$, respectively, on day 20 and by 57.08 and $43.29 \%$, respectively, on day 30 in 2017. However, the DCPTA application partially reversed the increases in the protease activity and free amino acid contents caused by drought. In the drought +DCPTA treatment compared with the control, the protease activity and free amino acid contents increased by 78.47 and $24.77 \%$, respectively, on day 20 and by 16.46 and $6.62 \%$, respectively, on day 30 in 2016 and increased 


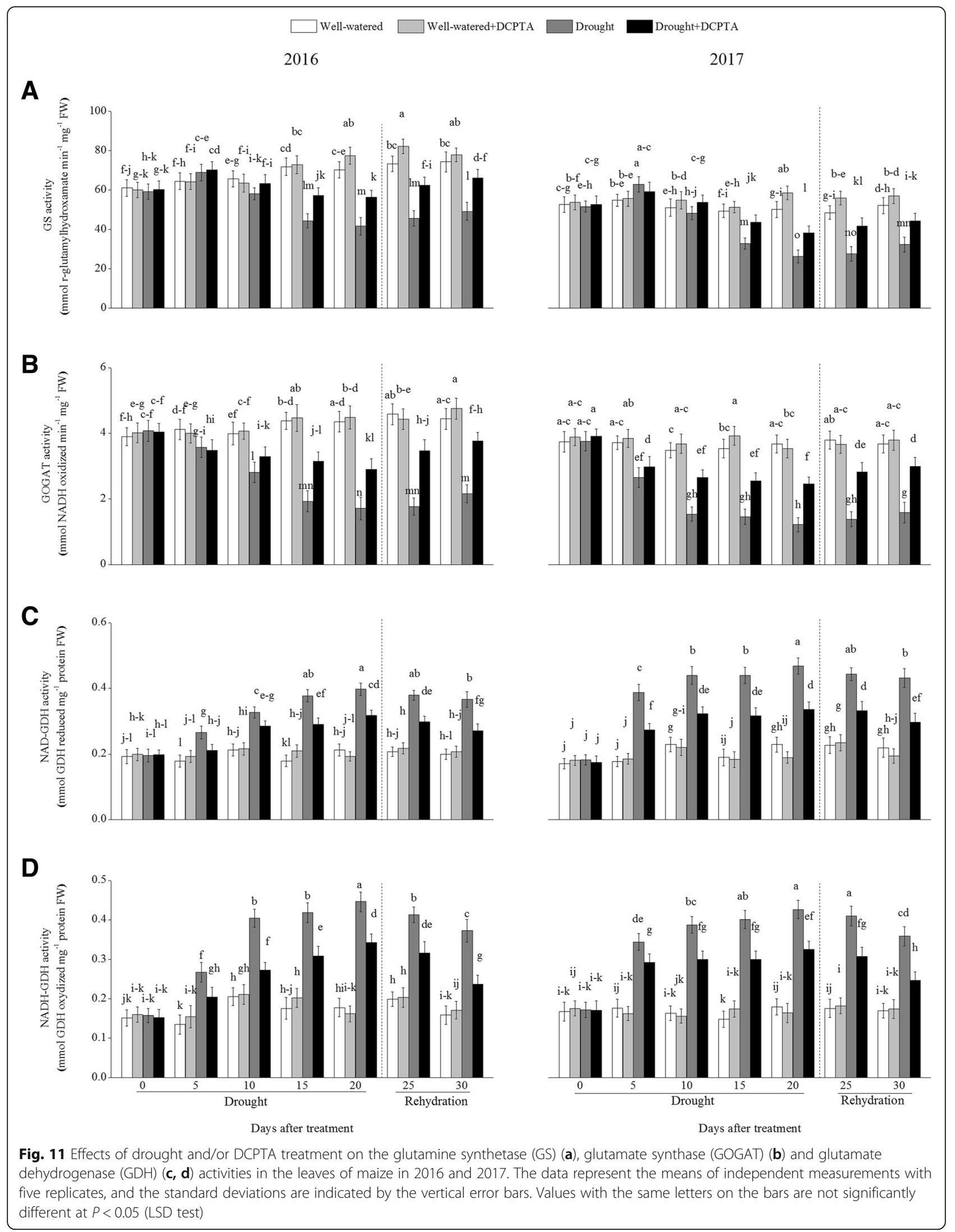




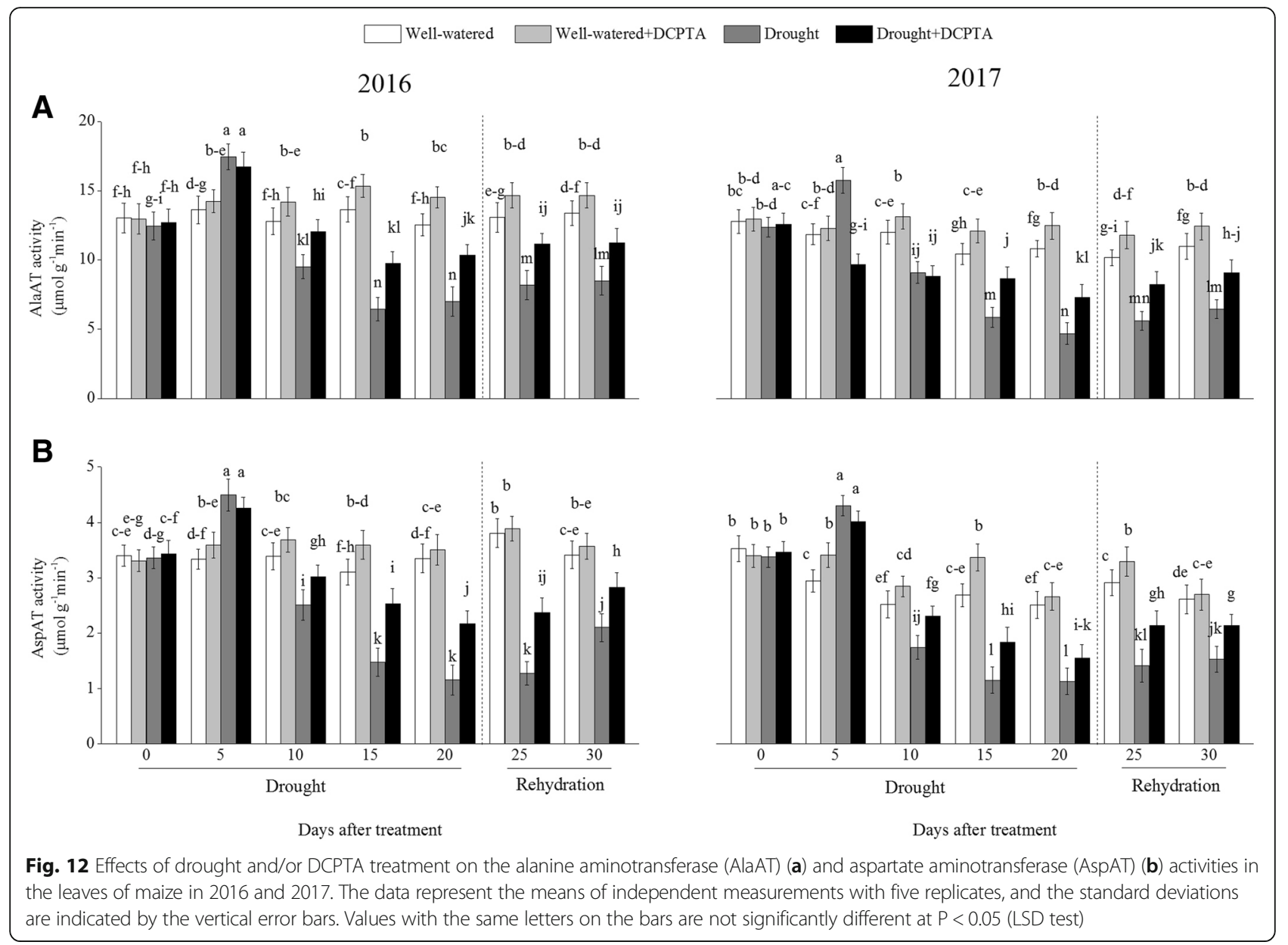

by 65.41 and $30.24 \%$, respectively, on day 20 and 14.50 and $13.57 \%$, respectively, on day 30 in 2017 .

In contrast, drought led to a marked decrease in the foliar protein content (Fig. 13b). In the drought treatment compared with the control, the foliar protein content decreased by $35.51 \%$ on day 20 and by $18.32 \%$ on day 30 in 2016 and decreased by $44.81 \%$ on day 20 and by $22.50 \%$ on day 30 in 2017. The DCPTA application suppressed the decrease in the foliar protein content induced by drought. In the drought+DCPTA treatment compared with the control, the foliar protein content decreased by $19.54 \%$ on day 20 and by $7.25 \%$ on day 30 in 2016 and decreased by $25.46 \%$ on day 20 and by $10.30 \%$ on day 30 in 2017. Significant differences between the foliar protein contents of the well-watered treatment and well-watered+DCPTA treatment were observed on day 10 in 2017 and on day 15 in 2017, and significant differences between the free amino acid contents of these treatments were observed on day 10 in 2017.

\section{Discussion}

Similar to previous reports for tomato [22] and wheat [19], drought significantly diminished the $\mathrm{NO}_{3}{ }^{-}$content in maize leaves in both the DCPTA-treated and non-treated leaves (Fig. 9a). This decrease may be explained by drought-induced inhibitions in nitrate uptake from the roots and/or nitrate transport. However, in this study, the reduction in the non-treated leaves was greater than that in the DCPTA-treated leaves.

In this study, there was a significant difference between the RLD and RSD of the well-watered treatment and DCPTA treatment in $0-20 \mathrm{~cm}$ and $0-30 \mathrm{~cm}$ in 2016 and 2017 on day 30 (Fig. 3b and d). This result suggests that DCPTA promoted root development in maize under well-watered conditions. Interestingly, under drought conditions, the DCPTA application significantly increased RLD, RSD and the root RGR (Fig. 3a-d). These results indicate that the DCPTA application also promoted maize root growth and improved the spatial and temporal distribution of roots, which was beneficial to $\mathrm{NO}_{3}{ }^{-}$uptake under drought conditions.

The xylem sap transports water and nutrients from the roots throughout the plant and depends on transpiration intensity and root pressure. The increased root hydraulic conductivity and flow rate of root-bleeding sap induced by the DCPTA application may due to the 


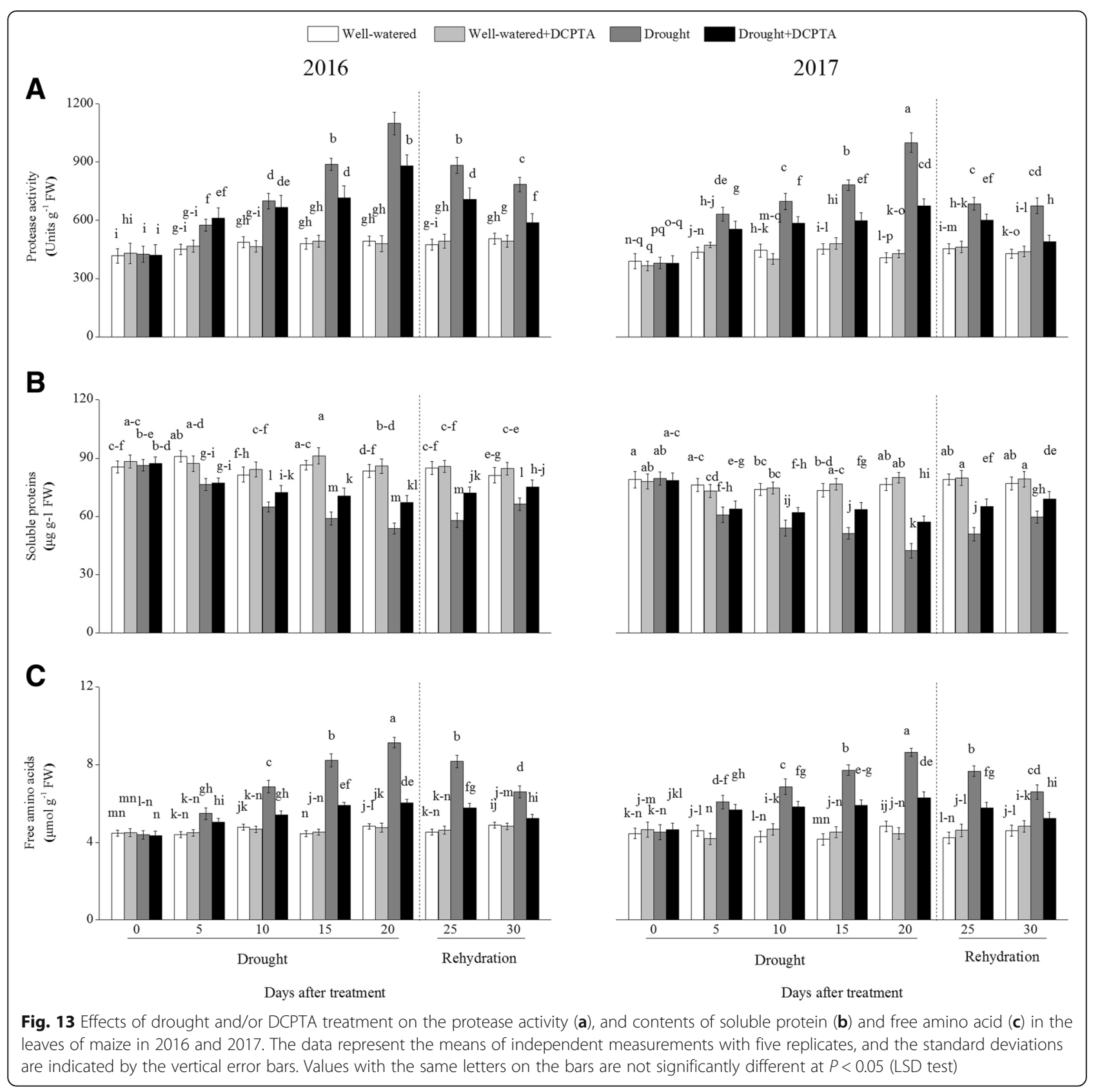

enhanced root pressure, which depend on physiological activity of the whole root system (Fig. 4a and b) [23, 24]. In addition, the $\mathrm{NO}_{3}{ }^{-}$delivery rate in the presence of DCPTA was significantly higher than that without DCPTA under drought conditions, which may partly result from the improved $\mathrm{NO}_{3}{ }^{-}$absorption and enhanced root pressure induced by DCPTA (Fig. 4c). The stable RWC in the drought+DCPTA treatment suggests an abundant supply water to the aboveground parts, and balanced transpirational loss and water uptake under drought conditions; as a result, the DCPTA-treated plants maintained Gs, which reduced the leaf epidermal resistance and promoted the mass flow of water to the leaf surface and the transportation of the $\mathrm{NO}_{3}{ }^{-}$required for $\mathrm{N}$ metabolism in leaves (Figs. 5 and $6 \mathrm{~b}$ ). Under drought conditions, increases in the foliar $\mathrm{NO}_{3}{ }^{-}$were observed in the DCPTA-treated plants (Fig. 9b).

Whether stomatal or non-stomatal factors are the main cause of a reduced Pn may be determined by changes in Gs and Ci [25]. During the early period of drought, the change of $\mathrm{Ci}$ were accompanied by continuously declined Gs, then Gs decreases, but $\mathrm{Ci}$ shows an increase (Fig. 6b and d). Thus, the decrease of the Pn in drought-treated plants was mainly attributed to stomatal 
limitations firstly, and then, non-stomatal limitations induced by the damage of photochemical mechanism, partly reflected by damaged chloroplast (Figs. 6a and 7). However, DCPTA application maintains relatively high Gs, ensuring the availability of $\mathrm{CO}_{2}$ for the carbon reduction cycle. Simultaneously, the DCPTA application delayed the increase in $\mathrm{Ci}$ and protected the chloroplast ultrastructure against drought-induced oxidative damage, which suggests that DCPTA can protect the photochemical mechanism and, as a result, ensures a more efficient photosynthesis process after rehydration. Moreover, similar to previous studies on spruce [7], sugar beets [9] and guayule [10], DCPTA application also promoted photosynthesis under well-watered conditions.

In most plants, nitrate reduction occurs in leaves. $\mathrm{NO}_{3}{ }^{-}$, after being taken up into the leaf cell, is converted to $\mathrm{NH}_{4}{ }^{+}$by two successive steps catalysed by NR and NiR. NR, the rate-limiting enzyme of nitrogen assimilation, is highly sensitive to stress [26]. Similar to previous studies on wheat and barley, the NR activity continuously declined in response to drought (Fig. 10a) [18, 19]. As a typical nitrate-induced enzyme, NR activity is primarily regulated by the $\mathrm{NO}_{3}{ }^{-}$concentration in the leaves [27]. The up-regulation of foliar NR activity in the drought+DCPTA treatment may result from the increase in the foliar $\mathrm{NO}_{3}{ }^{-}$content (Fig. 9a). Moreover, the reduction in the foliar NiR activity under drought conditions was significantly reversed by the application of DCPTA, which may be because the DCPTA-stabilized photosynthesis resulted in a sufficient supply of $\mathrm{Fd}_{\text {red }}$ (Figs. 6a and 10b), thus promoting the conversion of $\mathrm{NO}_{2}{ }^{-}$to $\mathrm{NH}_{4}{ }^{+}$. The present results indicate that DCPTA treatment could maintain a high $\mathrm{NO}_{3}{ }^{-}$assimilation ability in maize under drought conditions.

Although the foliar NR and NiR activities declined during the drought period, the foliar $\mathrm{NH}_{4}{ }^{+}$content exhibited an increasing tendency in our experiment (Fig. 9c). This increase may be associated with the glycine oxidation in activated photorespiration, which is induced by decreases in Ci levels under drought conditions [28]. The increased Gs induced by DCPTA was beneficial to the increase in $\mathrm{CO}_{2}$ in the cellular spaces of the leaf, implying that photorespiration was partly alleviated (Fig. $6 \mathrm{~b}$ ).

In plants cells, excessive levels of $\mathrm{NH}_{4}{ }^{+}$are destructive, and the major $\mathrm{NH}_{4}{ }^{+}$assimilation pathway is the GS/ GOGAT cycle in higher plants. When the GS/GOGAT cycle is suppressed and the $\mathrm{NH}_{4}{ }^{+}$content rises continuously under stress, $\mathrm{NH}_{4}{ }^{+}$could serve as a substrate to form glutamate via the reversible amination of 2-OG, the process is catalyzed by $\mathrm{GDH}$, although the enzyme has a lower affinity for $\mathrm{NH}_{4}{ }^{+}$[29]. In general, drought inhibited $\mathrm{NH}_{4}{ }^{+}$assimilation [30]. During the early period of drought, GDH activity increased sharply, GS activity increased slightly (Fig. 11a-d). These results suggest that accelerated $\mathrm{NH}_{4}{ }^{+}$assimilation in maize may be an adaptive mechanism to produce more glutamate and eliminate the accumulation of excess foliar $\mathrm{NH}_{4}{ }^{+}$. Subsequently, the GS and GOGAT activities decreased, which may have resulted from an inadequate supply of energy and 2-OG because of photosynthetic inhibition and decreased ICDH activity (Fig. 8).

The DCPTA application altered the major $\mathrm{NH}_{4}{ }^{+}$assimilation pathway, maintained the GOGAT/GS cycle and suppressed the GDH pathway, which may have contributed to maintaining the conversion of $\mathrm{NH}_{4}{ }^{+}$to glutamine and the subsequent formation of glutamate from glutamine. This result may occur because the photosynthetic stability and ICDH activity induced by the DCPTA application promoted 2-OG synthesis and the reducing power (i.e., NADPH, ATP, or $\mathrm{Fd}_{\text {red }}$ ) in plants during the drought period, thus providing the GS/GOGAT cycle with relatively sufficient substrates and energy and favouring the enhancement of foliar GOGAT and GS activities [31]. As a result, with the application of DCPTA, drought had less of an effect on the activities of GS and GOGAT.

Although DCPTA promoted $\mathrm{NO}_{3}{ }^{-}$assimilation, as expressed by the increased $\mathrm{NR}$ and $\mathrm{NiR}$ activities (Fig. 10a and b), this treatment compared to the drought treatment caused significant decreases in the $\mathrm{NH}_{4}{ }^{+}$content, which means that exogenous DCPTA resulted in the integration of $\mathrm{NH}_{4}{ }^{+}$into the structure of organic compounds, thereby contributing to the reduction in the $\mathrm{NH}_{4}{ }^{+}$content. Therefore, the DCPTA application effectively modulated the activities of ICDH, GS, GOGAT and GDH and accelerated the conversion of $\mathrm{NH}_{4}^{+}$to glutamate, which is the precursor of other amino acids.

Transamination is a key step in the biosynthesis of various amino acids from glutamate, with the availability of $C$ skeletons from the Krebs cycle [32]. In our studies, both the aminotransferases studied, AlaAT and AspAT, showed increased activities in maize during the early drought period (Fig. 12a and b). Such increases in aminotransferases activities under drought conditions might help in the synthesis of increased amounts of amino acids that act as compatible cytoplasmic solutes and protect cell organelles and biomolecules, thus reducing the adverse effects of drought on maize [33]. Subsequently, the AlaAT and AspAT activities decreased, which may be attributable to the weakened GS/ GOGAT pathway (Fig. 11a and b) [34]. Moreover, stable aminotransferase activities were observed in DCPTA-treated plants. This finding may be associated with increased GS/GOGAT activities, which can generate more glutamate to serve as a substrate for transamination reactions in maize treated with DCPTA under drought conditions.

Most soluble proteins are enzymes that participate in various metabolic pathways in plants; therefore, the soluble protein content is considered one of the most 
important indices reflecting the overall metabolic level in plants. Protein synthesis in plants is very sensitive to abiotic stresses and is positively correlated with stress tolerance [19]. Free amino acids are the building blocks of proteins. Drought increased the free amino acid contents, which may mainly be attributed to the increased AlaAT and AspAT activities in the early drought period and the promotion of protein degradation (Figs. 12a, b, 13a, b, c) [35]. However, DCPTA-treated seedlings maintained higher soluble protein levels and lower free amino acid levels than did non-DCPTA-treated seedlings in response to drought. This result may occur because DCPTA inhibited protein degradation by stable protease activities and maintained protein stability, ensuring the series of physiological and biochemical processes that occur normally under stress conditions. Additionally, the DCPTA application increased the amino acid contents under well-watered conditions, which may be attributable to the promoted biosynthesis and accumulation of amino acids, which ultimately improved plant growth and development [36].

\section{Conclusions}

The present study suggested that DCPTA treatment increased $\mathrm{NO}_{3}{ }^{-}$uptake and the long-distance transportation of $\mathrm{NO}_{3}{ }^{-}$from the roots to the leaves via the production of excess roots and maintained a stabilized transpiration rate. The increased foliar $\mathrm{NO}_{3}{ }^{-}$content up-regulated NR activity and maintained a high $\mathrm{N}$ assimilation ability that was restrained by drought. Exogenous DCPTA effectively regulated the ICDH, GS, GOGAT and GDH activities to speed up the conversion of $\mathrm{NH}_{4}{ }^{+}$to Glu, reduced the toxicity of excess $\mathrm{NH}_{4}{ }^{+}$to the plant, and accelerated the synthesis of proteins and amino acids. Moreover, DCPTA treatment maintained increased the photosynthetic capacity, supply nitrogen metabolism of energy and carbon skeleton thus alleviating the inhibition of growth by drought in maize.

\section{Methods}

Plant material, growth conditions, design and sampling Seeds of the maize cultivar ZhengDan 958 and DCPTA were obtained from the Henan Academy of Agricultural Sciences in China and the China Zhengzhou Zhengshi Chemical Limited Company, respectively.

These experiments were performed in 2016 and 2017 at the Experimental Station of Northeast Agricultural
University, Harbin (126 $\left.73^{\prime} \mathrm{E}, 4^{\circ} 73^{\prime} \mathrm{N}\right)$, Heilongjiang province, China. The research field area has a temperate continental monsoon climate. The rainfall and mean temperature data during the study period (2016 and 2017, May-October) are listed in Additional file 2. Pits (inner length, $10 \mathrm{~m}$; width, $7 \mathrm{~m}$; and height, $1.2 \mathrm{~m}$ ) in the field were used as experiment containers (Additional file 3). Plastic sheets were used to cover the inner sides of the pits, and a rain-proof shed was used to ensure the crops were solely dependent on soil moisture and irrigation over the course of the experiment to maintain the soil water conditions. The soil used was Chernozem and was sieved (pore size, $1 \mathrm{~cm}$ ) and diluted with vermiculite (particle diameter, 4-8 $\mathrm{mm}$; soil to vermiculite, $v / \mathrm{v}, 2: 1$ ). Before planting, soil chemical analysis was conducted according to Cottenie et al. (1982) [37], and the results are presented in Table 1. Fertilization was carried out by adding ammonium nitrate $(33.5 \% \mathrm{~N})$, calcium superphosphate $\left(15.5 \% \mathrm{P}_{2} \mathrm{O}_{5}\right)$, and potassium sulfate $\left(48 \% \mathrm{~K}_{2} \mathrm{O}\right)$ at the rates of $8.0,8.0$ and $20 \mathrm{~kg} \mathrm{pit}^{-1}$, respectively, before planting. No fertilizer was applied after planting. All containers were watered to $85 \%$ before planting. The seeds were manually sown on 2nd May 2016 and 4th May 2017 and were harvested on 7th October 2016 and 3rd October 2017, respectively. Three seeds were sowed per hole to ensure germination, and only the healthiest seedling within 20 days was kept at each site. Each container consisted of 10 rows, and the plant-to-plant and row-to-row distances were $20 \mathrm{~cm}$ and $65 \mathrm{~cm}$, respectively. In addition, the ground around the containers was manually sown with the same plant-to-plant and row-to-row distances. The control of plant diseases and insect pests was conducted by managers.

The maize at the nine-leaf stage (during the pre-female inflorescence emergence stage) were treated as follows:

(1) plants were irrigated continuously and sprayed with either $10 \mathrm{~mL}$ water (well-watered) or DCPTA (wellwatered+DCPTA) per plant;

(2) irrigation was stopped to form the drought conditions and sprayed with $10 \mathrm{~mL}$ of either water (drought) or DCPTA (drought +DCPTA) per plant; plants were rehydrated after 20 days of drought treatment.

The concentrations of DCPTA $(25 \mathrm{mg} / \mathrm{L})$ were based on the results of previous screening experiments, and

Table 1 Chemical properties of the used soil

\begin{tabular}{lllllllll}
\hline Year & $\mathrm{pH}$ & $\begin{array}{l}\mathrm{HCO}_{3}^{-} \\
+\mathrm{CO}_{3}^{2-} \\
\left(\mathrm{mg} \mathrm{kg}^{-1}\right)\end{array}$ & $\begin{array}{l}\mathrm{Cl}^{-} \\
\left(\mathrm{mg} \mathrm{kg}^{-1}\right)\end{array}$ & $\begin{array}{l}\mathrm{SO}_{4}^{2-} \\
\left(\mathrm{mg} \mathrm{kg}^{-1}\right)\end{array}$ & $\begin{array}{l}\mathrm{Ca}_{2}^{+} \\
\left(\mathrm{mg} \mathrm{kg}^{-1}\right)\end{array}$ & $\begin{array}{l}\mathrm{Mg}_{2}^{+} \\
\left(\mathrm{mg} \mathrm{kg}^{-1}\right)\end{array}$ & $\begin{array}{l}\mathrm{Na}^{+} \\
\left(\mathrm{mg} \mathrm{kg}^{-1}\right)\end{array}$ & $\begin{array}{l}\mathrm{K}^{+} \\
\left(\mathrm{mg} \mathrm{kg}^{-1}\right)\end{array}$ \\
\hline 2016 & 7.2 & 204.3 & 297.6 & 463.8 & 87.4 & 37.6 & $\begin{array}{l}\mathrm{N} \\
\left(\mathrm{mg} \mathrm{kg}^{-1}\right) \\
\left(\mathrm{mg} \mathrm{kg}^{-1}\right)\end{array}$ \\
2017 & 7.1 & 201.7 & 302.5 & 446.2 & 90.3 & 40.9 & 3.9 & 28.9 \\
\hline
\end{tabular}


Tween-20 (0.03\%) was added as a surfactant to the solution for spraying. Each treatment had five replicates, and experiments were performed in a completely randomized design. The dynamic changes in soil water contents during the experimental stage are exhibited in Additional file 4.

Random plants from each treatment were sampled on days $0,5,10,15,20,25$ and 30 . For leaf sampling, the middle part of the 9th leaf (numbered basipetally) was sampled for analysis of leaf gas exchange, and the same part of the leaf was stored at $-80^{\circ} \mathrm{C}$ after immersion in liquid nitrogen for $30 \mathrm{~min}$ for determination of physiological parameters. For root sampling, a hand-held soil auger (inner diameter of $20 \mathrm{~cm}$ ) was used to obtain soil cores from 0 to $100 \mathrm{~cm}$ depth of the soil profile at $10 \mathrm{~cm}$ increments. The soil cores were soaked in a plastic container overnight, and roots were stirred and sieved through a mesh $\left(400\right.$ holes $\left.\mathrm{cm}^{-2}\right)$. The soil cores were the carefully washed by swirling water through the cores. The soil material and old dead roots debris were manually separated from the live roots.

No permissions or licenses were needed to obtain our plant sample.

\section{Plant measurement and analysis \\ Relative growth rate (RGR) and plant productivity}

The shoots and roots of maize were oven dried at $105^{\circ} \mathrm{C}$ for $45 \mathrm{~min}$ and then held at $80^{\circ} \mathrm{C}$ for $48 \mathrm{~h}$; the shoot and root dry weights plant ${ }^{-1}$ were determined soon afterwards. The RGR was determined as follows: RGR (fresh weight $)=[\ln$ (final dry weight) $-\ln$ (initial dry weight) $] /$ (duration of treatment days) [38]. A leaf area metre (Li-COR 3100; Li-COR, Lincoln, NE, USA) was used to estimate the leaf area; number of grains plant $^{-1}(\mathrm{GN})$ and grain yield plant ${ }^{-1}(\mathrm{GY})$ were recorded at the maize physiological maturity stage.

Leaf relative water content (RWC) and soil water content (SWC) The RWC and SWC were determined according to the methods of Machado and Paulsen (2001) [39] and Turner (1981) [40], respectively.

The RWC was determined on fresh leaf disks $(2 \times 2$ $\mathrm{cm}$ ) from the middle part of the 8th leaves (numbered basipetally). After they were weighed (FW), the disks were immersed in distilled water at $25^{\circ} \mathrm{C}$ overnight to obtain the turgid weight (TW). The leaves were dried at $80^{\circ} \mathrm{C}$ for $48 \mathrm{~h}$ and then weighed a third time (DW). RWC was calculated as follows:

$$
\operatorname{RWC}(\%)=[(\mathrm{FW}-\mathrm{DW}) /(\mathrm{TW}-\mathrm{DW})] \times 100 \% .
$$

SWC was determined in the soil from the internal area of each container. After being weighed (FW), the soil portion was dried at $85^{\circ} \mathrm{C}$ for $96 \mathrm{~h}$ and then weighed (DW). SWC was calculated as follows:

$$
\operatorname{SWC}(\%)=[(\mathrm{FW}-\mathrm{DW}) / \mathrm{DW}] \times 100 \% \text {. }
$$

\section{Gas exchange}

The photosynthetic rate $(\mathrm{Pn})$, transpiration rate $(\mathrm{Tr})$, stomatal conductance (Gs), and intercellular $\mathrm{CO}_{2}$ concentration $(\mathrm{Ci})$ values were determined with a portable photosynthesis system (LI-6400XT; LI-COR Biosciences, Lincoln, NE, USA) between at 13:00 14:00 h. The 6- $\mathrm{cm}^{2}$ leaf chamber was used, and the photo flux density was $1000 \mathrm{lmol} \mathrm{m}^{-2} \mathrm{~s}^{-1}$.

\section{Transmission electron microscopy of chloroplasts}

Observations were performed according to the description of $\mathrm{Hu}$ et al. (2014) [41], and the chloroplast ultrastructure was observed under a H-7650 transmission electron microscope (manufacture: Hitachi, Japan).

\section{Root morphological traits, root hydraulic conductivity, and the collection of root-bleeding sap}

Roots from each soil core were scanned using a digital scanner (Epson V700, Indonesia). The root images were analysed using the WinRHIZO Image Analysis system (Version 2013e) (Regent Instruments Inc., Canada). The root length density (RLD, $\mathrm{cm}$ root $\mathrm{cm}^{-3}$ soil) and root square area density (RSD, $\mathrm{cm}^{2}$ root $\mathrm{cm}^{-3}$ soil) were calculated according to the method described by Mosaddeghi et al. (2009) [42].

The hydrostatic root hydraulic conductivity (Lp) was measured with a Scholander pressure chamber according to the method described by López-Pérez et al. (2007) [43].

The tools used for collection of root-bleeding sap are exhibited in Additional file 5 . The plants were cut by scissors at $10-12 \mathrm{~cm}$ above the soil surface at 18:00-19:00. Centrifuge tubes (inner diameter $40 \mathrm{~mm}$ ) with cotton were placed on the upper end of the stalks, and the stalk joints and centrifuge tubes were wrapped by plastic film to keep impurities and insects out. The bleeding sap was collected for $12 \mathrm{~h}$; then, the cotton was extracted from each centrifuge tube and placed into a glass syringe $(100 \mathrm{ml})$, and the root-bleeding sap was squeezed out for volume measurement. The $\mathrm{NO}_{3}{ }^{-}$content in the root-bleeding sap was determined by AA3 Continuous Flow Analytical System (Seal, Germany) according to Guan et al. (2014) [44]. The flow rate of the root-bleeding sap and the $\mathrm{NO}_{3}{ }^{-}$delivery rate were expressed as $\mathrm{ml} \mathrm{h}^{-1}$ root $^{-1}$ and $\mu \mathrm{g} \mathrm{h}^{-1}$ root $^{-1}$, respectively.

\section{Foliar $\mathrm{NO}_{3}{ }^{-}, \mathrm{NO}_{2}^{-}$and $\mathrm{NH}_{4}{ }^{+}$contents}

The foliar $\mathrm{NO}_{3}{ }^{-}$content determination by the reduction of $\mathrm{NO}_{3}{ }^{-}$to $\mathrm{NO}_{2}{ }^{-}$followed the salicylic acid methods of Cataldo et al. (1975) [45], the absorbance was monitored at $410 \mathrm{~nm}$. The foliar $\mathrm{NO}_{2}^{-}$content was determined 
using the method described by Barro et al. (1991) [46]. The $\mathrm{NO}_{2}{ }^{-}$content was calculated according to the standard curve obtained by known concentrations of $\mathrm{KNO}_{3}$. The $\mathrm{NH}_{4}{ }^{+}$content was determined by measuring the absorbance changes at $620 \mathrm{~nm}$, as described by Weber (2007) [47]. The $\mathrm{NH}_{4}{ }^{+}$content was calculated according to the standard curve obtained by known concentrations of $\left(\mathrm{NH}_{4}\right)_{2} \mathrm{SO}_{4}$.

\section{Enzyme activities involved in nitrogen metabolism}

The activities of foliar NR and NiR were measured based on the conversion of $\mathrm{NO}_{3}{ }^{-}$to $\mathrm{NO}_{2}{ }^{-}$and $\mathrm{NO}_{3}{ }^{-}$to $\mathrm{NH}_{4}{ }^{+}$, following the methods of Barro et al. (1991) [46], and Ida and Morita (1973) [48], respectively. One NR and $\mathrm{NiR}$ unit was expressed as the enzyme amount required for the conversion of $1 \mathrm{mmol}$ of $\mathrm{NO}_{3}{ }^{-}$to $\mathrm{NO}_{2}{ }^{-}$per hour and the enzyme amount required for the conversion of $1 \mathrm{mmol}$ of $\mathrm{NO}_{3}{ }^{-}$to $\mathrm{NH}_{4}{ }^{+} \mathrm{min}^{-1}$, respectively. GS activity was measured according to the methods of O'Neal and Joy (1973) [49]. One unit of GS was expressed as the enzyme amount required to catalyse the formation of $1 \mathrm{mmol}$ of glutamylmonohydroxamate per min. The results were expressed as $\mu$ mol NADH used per minute per milligram of Pro. The GOGAT activity was measured based on the conversion of 2-ketoglutarate to glutamate, following the methods of Groat and Vance (1981) [50]. One unit of GOGAT was expressed as the number of enzymes catalysing the oxidation of $1 \mathrm{mmol}$ of NADH per min. The deaminating GDH activity (NAD-GDH) and aminating GDH activity (NADH-GDH) were determined by recording the reduction of NAD and the oxidation of NADH, respectively, as described by Groat and Vance (1981) [50]. One unit of GDH was calculated in units of mmol of NADH oxidized/NAD reduced per minute. Isocitrate dehydrogenase (ICDH) was assayed according to the method of Lòpez-Millàn et al. (2000) [51].The activity was expressed as $\mathrm{U}$ per minute per milligram of protein.

\section{Activity of AlaAT and AspAT}

The AlaAT and AspAT activities were determined according to the methods of Jia et al. (2015) [52]. Enzyme activity was expressed as $\mu \mathrm{mol} \mathrm{g}{ }^{-1} \mathrm{~min}^{-1}$.

\section{Contents of free amino acids and soluble proteins and protease activity}

The free amino acid contents were assayed with the ninhydrin reagent method according to Yemm and Cocking (1955) [53], followed by absorbance readings at $570 \mathrm{~nm}$ using glycine as the standard. The soluble protein contents were determined using the Coomassie Brilliant Blue G-250 reagent following the description of Bradford (1976) [54], followed by absorbance readings at $595 \mathrm{~nm}$ using bovine serum albumin as the standard. Protease activity was determined by the casein digestion assay described by Drapeau (1974) [55]. By this method, one unit is the number of enzymes required to release acid-soluble fragments equivalent to $0.001 \mathrm{~A} 280$ per minute at $37^{\circ} \mathrm{C}$ and $\mathrm{pH} 7.8$.

\section{Statistical analysis}

The data were analysed using SPSS 17.0 and all the values are presented as the mean $\pm \mathrm{SE}$. The means were separated using the least significant difference (LSD) test at the $5 \%$ probability level (Additional file 6).

\section{Additional files}

Additional file 1: Leaf phenotypic features of the maize seedlings after 30 days of treatment with drought and/or DCPTA in 2016 and 2017. (JPG 531 kb) Additional file 2: The rainfall (bar) and mean temperature (line) data during the study period (2016 and 2017, May-October). (JPG 68 kb)

Additional file 3: The pits (inner length, $10 \mathrm{~m}$; width, $7 \mathrm{~m}$; and height, $1.2 \mathrm{~m}$ ) used for this study and the plastic sheets used to cover inner sides of the pits. (JPG $513 \mathrm{~kb}$ )

Additional file 4: Changes in the soil water content (SWC) in 2016 and 2017. The data represent the means of independent measurements with five replicates, and the standard deviations are indicated by the vertical error bars. Values with the same letters on the bars are not significantly different at $P<0.05$ (LSD test). (JPG $325 \mathrm{~kb}$ )

Additional file 5: The tools used for the collection of bleeding sap. Cotton (A), centrifuge tube (B), scissors (C), plastic film (D), and deionized water (E). (JPG $471 \mathrm{~kb}$ )

Additional file 6: Research data. (XLSX 99 kb)

\section{Abbreviations}

AlaAT: Alanine aminotransferase; AspAT: Aspartate aminotransferase; Ci: Intercellular $\mathrm{CO}_{2}$ concentration; DCPTA: 2-(3,4-Dichlorophenoxy) triethylamine; Fdred: Reduction-ferredoxin; GDH: Glutamate dehydrogenase; GOGAT: Glutamine oxoglutarate aminotransferase; GS: Glutamine synthase; Gs: Stomatal conductance; ICDH: Isocitrate dehydrogenase; Lp: Root hydraulic conductivity; $\mathrm{N}$ : Nitrogen; $\mathrm{NH}_{4}^{+}$: Ammonium; NiR: Nitrite reductase; $\mathrm{NO}_{2}{ }^{-}$: Nitrite; $\mathrm{NO}_{3}{ }^{-}$: Nitrate; NR: Nitrate reductase; Pn: Net photosynthetic rate; RGR: Relative growth rate; RLD: Root length density; RSD: Root surface area density; RWC: Leaf relative water content; SWC: Soil water content;

Tr: Transpiration rate

\section{Acknowledgments}

The manuscript has been released as a pre-print at https://www.biorxiv.org/ content/early/2018/08/04/385203, and has not been peer-reviewed before.

\section{Funding}

This work was supported by the National Key Research and Development Program of China (Grant Nos. 2017 YFD0300506 and 2016YFD0300103), and the "Academic Backbone" Project of Northeast Agricultural University (Grant No. 17XG23). The funding bodies had no roles in the design of the study and collection, analysis, and interpretation of data and in writing the manuscript.

Availability of data and materials

The datasets used and/or analysed during the current study are available from the corresponding author on reasonable request.

\section{Authors' contributions}

$T L X$ performed the entire experiment and drafted the manuscript, $L J$ gathered the data and analysed the results. CoFL, CaFL and WHL designed the entire experiment. SW and WRG were in charge of manuscript revisions. MQW and LGZ helped to interpret the results and prepare the manuscript. All the authors read and approved the final manuscript. 


\section{Ethics approval and consent to participate}

Not applicable.

\section{Consent for publication}

Not applicable.

\section{Competing interests}

The authors declare that they have no competing interests.

\section{Publisher's Note}

Springer Nature remains neutral with regard to jurisdictional claims in published maps and institutional affiliations.

\section{Author details}

${ }^{1}$ College of Agriculture, Northeast Agricultural University, No. 600, Changjiang Street, Xiangfang District, Harbin, China. ${ }^{2}$ Maize Research Institute, Heilongjiang Academy of Agricultural Sciences, No. 368, Xuefu Street, Nangang District, Harbin, China. ${ }^{3}$ Institute of Crop Science, Chinese Academy of Agricultural Sciences, No. 12, Zhongguancunnan Street, Haidian District, Beijing, China.

\section{Received: 11 December 2018 Accepted: 11 March 2019}

\section{Published online: 19 March 2019}

\section{References}

1. Trenberth KE, Dai A, Schrier GVD, Jones PD, Barichivich J, Briffa KR, et al. Global warming and changes in drought. Nat Clim Chang. 2014;4(1):17-22.

2. Nuccio ML, Wu J, Mowers R, Zhou HP, Meghii M, Primavesi LF, et al. Expression of trehalose-6-phosphate phosphatase in maize ears improves yield in well-watered and drought conditions. Nat Biotechnol. 2015;33(8): 862-9.

3. Ziyomo C, Bernardo R. Drought tolerance in maize: indirect selection through secondary traits versus genomewide selection. Crop Sci. 2013;53(4): 1269-75.

4. Schiermeier Q. The parched planet: water on tap. Nature. 2014:510(7505):326-8.

5. Zhao J, Xue Q, Jessup KE, Hao B, Hou X, Marek TH, et al. Yield and water use of drought-tolerant maize hybrids in a semiarid environment. Field Crop Res. 2018;216:1-9.

6. Ali F, Bano A, Fazal A. Recent methods of drought stress tolerance in plants. Plant Growth Regul. 2017;82(3):1-13.

7. Keithly $\mathrm{JH}$, Yokoyama $\mathrm{H}$, Gausman $\mathrm{H}$. Enhanced yield of tomato in response to 2-(3,4-dichlorophenoxy) triethylamine (DCPTA). Plant Growth Regul. 1990; $9(2): 127-36$

8. Wang YC, Gu WR, Xie TL, Li LJ, Sun Y, Zhang H, et al. Mixed compound of DCPTA and CCC increases maize yield by improving plant morphology and up-regulating photosynthetic capacity and antioxidants. PLoS One. 2016; 11(2):e0149404.

9. Keithly JH, Yokoyama H, Gausman HW. Effect of 2-(3,4-dichlorophenoxy) triethylamine (DCPTA) on the growth and development of sugarbeet. Plant Sci. 1990;68(1):57-64

10. Wan JH, Mendoza K. Effect of 2-(3,4-dichlorophenoxy) triethylamine on guayule (Parthenium argentatum) cell suspension cultures. J Agric Food Chem. 1992:40(5):924-6.

11. Gausman HW, Burd JD, Quisenberry J, Yokoyama H, Dilbeck R, Chan RB. Effect of 2-diethylaminoethyl-3,4-dichlorophenylether (DCPTA) on cotton plant (Gossypium hirsutum) growth and phenology. Nat Biotechnol. 1985; 3(3):255-7.

12. Benedict $\mathrm{CR}$, Rosenfield $\mathrm{CL}$, Mahan JR, Madhavan S, Yokoyama H. The chemical regulation of carotenoid biosynthesis in citrus. Plant Sci. 1985; 41(3):169-73.

13. Kusano M, Fukushima A, Redestig H, Saito K. Metabolomic approaches toward understanding nitrogen metabolism in plants. J Exp Bot. 2011;62(4):1439.

14. Rajasekhar VK, Oelmüller R. Regulation of induction of nitrate reductase and nitrite reductase in higher plants. Physiol Plant. 2010;71(4):517-21.

15. Chardon F, Noël V, Masclaux-Daubresse C. Exploring nue in crops and in arabidopsis ideotypes to improve yield and seed quality. J Exp Bot. 2012 63(9):3401

16. Slattery RA, Walker BJ, Weber A, Ort DR. The impacts of fluctuating light on crop performance. Plant Physiol. 2017;176:990-1003.
17. Nacer B, Gillen AM, Alemu M, Hirut K, Fisher DK, Smith JR, et al. Responses of nitrogen metabolism and seed nutrition to drought stress in soybean genotypes differing in slow-wilting phenotype. Front Plant Sci. 2013;4(1):498.

18. Robredo A, Pérez-López U, Miranda-Apodaca J, Lacuesta M, Mena-Petite A, Muñoz-Rueda A. Elevated $\mathrm{CO}_{2}$, reduces the drought effect on nitrogen metabolism in barley plants during drought and subsequent recovery. Environ Exp Bot. 2011;71(3):399-408.

19. Fresneau C, Ghashghaie J, Cornic G. Drought effect on nitrate reductase and sucrose-phosphate synthase activities in wheat (Triticum durum L.): role of leaf internal $\mathrm{CO}_{2}$. J Exp Bot. 2007;58(11):2983.

20. Xie TL, Gu WR, Meng Y, Li J, Li LJ, Wang YC, et al. Exogenous DCPTA ameliorates simulated drought conditions by improving the growth and photosynthetic capacity of maize seedlings. Sci Rep. 2017;7:12684.

21. Xie TL, Gu WR, Zhang LG, Li LJ, Qu DY, Li CF, et al. Modulating the antioxidant system by exogenous 2-(3,4-dichlorophenoxy) triethylamine in maize seedlings exposed to polyethylene glycol-simulated drought stress. PLoS One. 2018;13(9):e0203626.

22. Sánchez-Rodríguez E, Rubio-Wilhelmi MM, Ríos JJ, Blasco B, Rosales MÁ, Melgarejo $\mathrm{R}$, et al. Ammonia production and assimilation: its importance as a tolerance mechanism during moderate water deficit in tomato plants. J Plant Physiol. 2011:168(8):816.

23. Noguchi A, Kageyama M, Shinmachi F, Schmidhalter U, Hasegawa I. Potential for using plant xylem sap to evaluate inorganic nutrient availability in soil. Soil Sci Plant Nutr. 2005;51(3):343-50.

24. Liu P, Yin L, Deng X, Wang S, Tanaka K, Zhang S. Aquaporin-mediated increase in root hydraulic conductance is involved in silicon-induced improved root water uptake under osmotic stress in Sorghum bicolor L. J Exp Bot 2014:65(17):4747.

25. Bethke PC, Drew MC. Stomatal and nonstomatal components to inhibition of photosynthesis in leaves of capsicum annuum during progressive exposure to $\mathrm{NaCl}$ salinity. Plant Physiol. 1992;99(1):219-26.

26. Plett D, Holtham L, Baumann U, Kalashyan E, Francis K, Enju A, et al. Nitrogen assimilation system in maize is regulated by developmental and tissue-specific mechanisms. Plant Mol Biol. 2016:92(3):293-312

27. Chamizo-Ampudia A, Sanz-Luque E, Llamas A, Galvan A, Fernandez E. Nitrate reductase regulates plant nitric oxide homeostasis. Trends Plant Sci. 2017;22(3):163

28. Wang H, Wu Z, Han J, Zheng W, Yang C. Comparison of ion balance and nitrogen metabolism in old and young leaves of alkali-stressed rice plants. PLoS One. 2012;7(5):e37817.

29. Fontaine JX, Tercé-laforgue T, Armengaud P, Clément G, Renou JP, Pelletier $\mathrm{S}$, et al. Characterization of a nadh-dependent glutamate dehydrogenase mutant of arabidopsis demonstrates the key role of this enzyme in root carbon and nitrogen metabolism. Plant Cell. 2012;24(10):4044-65.

30. Naya L, Ladrera R, Ramos J, González EM, Arrese-lgor C, Minchin FR, et al. The response of carbon metabolism and antioxidant defenses of alfalfa nodules to drought stress and to the subsequent recovery of plants. Plant Physiol. 2007;144(2):1104

31. Du J, Shu S, An Y, Zhou H, Guo S, Sun J. Influence of exogenous spermidine on carbon-nitrogen metabolism under $\mathrm{ca}\left(\mathrm{NO}_{3}\right)_{2}$ stress in cucumber root. Plant Growth Regul. 2016:81(1):1-13.

32. Hodges M. Enzyme redundancy and the importance of 2-oxoglutarate in plant ammonium assimilation. J Exp Bot. 2000;53(370):905.

33. Munns R, Tester M. Mechanisms of salinity tolerance. Annu Rev Plant Biol. 2008;59(1):651-81.

34. Gangwar S, Singh VP. Indole acetic acid differently changes growth and nitrogen metabolism in Pisum sativum L. seedlings under chromium (VI) phytotoxicity: implication of oxidative stress. Sci Hortic-Amsteadam. 2011; 129(2):321-8.

35. Yang Y, Lu X, Bei Y, Li B, Jin S, Guo S, et al. Bottle gourd rootstock-grafting affects nitrogen metabolism in nacl-stressed watermelon leaves and enhances short-term salt tolerance. J Plant Physiol. 2013:170(7):653.

36. Talaat NB, Shawky BT. Dual application of 24-epibrassinolide and spermine confers drought stress tolerance in maize (Zea mays, L.) by modulating polyamine and protein metabolism. J. Plant Growth Regul. 2016:35(5):518-33.

37. Cottenie A, Verloo M, Kiekens L, Velghe G, Camerlynck R. Chemical analysis of plants and soils. Laboratory of analytical and agrochemistry. Ghent: State University of Ghent; 1982. p. 14-24.

38. Kingsbury RW, Epstein E, Pearcy RW. Physiological responses to salinity in selected lines of wheat. Plant Physiol. 1984;74(2):417-23. 
39. Machado S, Paulsen GM. Combined effects of drought and high temperature on waterrelations of wheat and sorghum. Plant Soil. 2001;233:179-87.

40. Turner NC. Techniques and experimental approaches for the measurement of plant water status. Plant Soil. 1981:58(1-3):339-66.

41. Hu L, Xiang L, Li Z, Zhou X, Zou Z, Hu X. The photoprotective role of spermidine in tomato seedlings under salinity-alkalinity stress. PLoS One. 2014;9(10):e1 10855.

42. Mosaddeghi MR, Mahboubi AA, Safadoust A. Short-term effects of tillage and manure on some soil physical properties and maize root growth in a sandy loam soil in western Iran. Soil Tillage Res. 2009;104(1):173-9.

43. López-Pérez L, Fernández-García N, Olmos E, Carvajal M. The phi thickening in roots of broccoli plants: an acclimation mechanism to salinity? Int J Plant Sci. 2007:168(8):1141-9.

44. Guan D, Al-Kaisi MM, Zhang Y, Duan L, Tan W, Zhang M, et al. Tillage practices affect biomass and grain yield through regulating root growth root-bleeding sap and nutrients uptake in summer maize. Field Crop Res. 2014;157(2):89-97.

45. Cataldo DA, Maroon M, Schrader LE, Youngs VL. Rapid colorimetric determination of nitrate in plant tissue by nitration of salicylic acid1 Commun Soil Sci Plant Anal. 1975;6(1):71-80.

46. Barro F, Fontes AG, Maldonado JM. Organic nitrogen content and nitrate and nitrite reductase activities in tritordeum and wheat grown under nitrate or ammonium. Plant Soil. 1991;135(2):251-6.

47. Weber AP. High-throughput colorimetric method for the parallel assay of glyoxylic acid and ammonium in a single extract. Anal Biochem. 2007; 362(1):151-3.

48. Ida S, Morita Y. Purification and general properties of spinach leaf nitrite reductase. Plant Cell Physiol. 1973;14(4):661-71.

49. O'Neal D, Joy KW. Glutamine synthetase of pea leaves. I. Purification, stabilization, and PH optima. Arch Biochem Biophys. 1973;159(1):113-22

50. Groat RG, Vance CP. Root and nodule enzymes of ammonia assimilation in two plant-conditioned symbiotically ineffective genotypes of alfalfa (Medicago sativa L.). Plant Physiol. 1982;69(3):614-8.

51. López-Millán AF, Abadía J. Responses of sugar beet roots to iron deficiency. Changes in carbon assimilation and oxygen use. Plant Physiol. 2000;124(2):885.

52. Jia Y, Zou D, Wang J, Liu H, Inayat MA, Sha H, et al. Effect of low water temperature at reproductive stage on yield and glutamate metabolism of rice (Oryza sativa, L.) in China. Field Crop Res. 2015;175:16-25.

53. Yemm EW, Cocking EC. The determination of amino-acids with ninhydrin. Analyst. 1955;80(80):209-14.

54. Bradford MM. A rapid and sensitive method for the quantitation of microgram quantities of protein utilizing the principle of protein-dye binding. Anal Biochem. 1976;72:248-54.

55. Drapeau G. Protease from Staphylococcus aureus. In: Lorand L, editor. Method of enzymology. New York: Academic Press; 1974. p. 469.

Ready to submit your research? Choose BMC and benefit from:

- fast, convenient online submission

- thorough peer review by experienced researchers in your field

- rapid publication on acceptance

- support for research data, including large and complex data types

- gold Open Access which fosters wider collaboration and increased citations

- maximum visibility for your research: over $100 \mathrm{M}$ website views per year

At $\mathrm{BMC}$, research is always in progress.

Learn more biomedcentral.com/submissions 